DEPARTMENT OF ECONOMICS

\title{
From High School to the High Chair: \\ Education and Fertility Timing
}

Jonathan James \& Sunčica Vujić

\author{
UNIVERSITY OF ANTWERP \\ Faculty of Applied Economics \\ City Campus \\ Prinsstraat 13, B.226 \\ AACSB B-2000 Antwerp \\ Tel. +32 (0)3 2654032 \\ Fax +32(0)3 2654799 \\ www.uantwerpen.be
}




\title{
FACULTY OF APPLIED ECONOMICS
}

\author{
DEPARTMENT OF ECONOMICS \\ From High School to the High Chair: \\ Education and Fertility Timing \\ Jonathan James \& Sunčica Vujić \\ RESEARCH PAPER 2016-005 \\ APRIL 2016
}
University of Antwerp, City Campus, Prinsstraat 13, B-2000 Antwerp, Belgium Research Administration - room B.226 phone: (32) 32654032
fax: (32) 32654799
e-mail: joeri.nys@uantwerpen.be

The research papers from the Faculty of Applied Economics are also available at www.repec.org

(Research Papers in Economics - RePEc)

$D / 2016 / 1169 / 005$ 


\title{
From High School to the High Chair: Education and Fertility Timing*
}

\author{
Jonathan James (University of Bath) \\ Sunčica Vujić (University of Antwerp)
}

April 21, 2016

\begin{abstract}
This paper examines the effect of education on the timing of fertility. First, we use an institutional rule that led to women obtaining qualifications due to their month of birth (Easter Leaving Rule). Second, we exploit a large expansion of post-compulsory schooling that occurred from the late 1980s to the early 1990s. This expansion resulted in the proportion of 18 year olds in full time education rising from around $17 \%$ in 1985 to over $35 \%$ in the late 1990s. We find that neither the exogenous increase in qualifications as a result of the Easter Leaving Rule nor the expansion in post-compulsory schooling led to a reduction in the probability of having a child as a teenager. However, we do find that both sources of variation in education led to delays in having a child. There is no evidence that the mechanism driving these findings are due to an incapacitation effect. Instead the results point to both a direct human capital effect and an improvement in labour market opportunities as a result of holding qualifications.
\end{abstract}

Keywords: Education; Fertility Timing.

JEL classification: I26, J13

${ }^{*}$ We would like thank the participants at the ESRC Multi-disciplinary Workshop on Education at the Institute for Social and Economic Research (ISER) at the University of Essex, the participants at the LEER Workshop on Education Economics at the Faculty of Business and Economics of KU Leuven, Campus Leuven, the participants at the Belgian day for labour economists (BDLE) at the Faculty of Business and Economics of KU Leuven, Campus Brussels, the participants at the Wim Meeusen Workshop at the Staffordshire University, the participants at the Royal Economics Society (RES) conference at the University of Sussex, the participants at the Second Workshop on Education Economics, organised by the Top Institute for Evidence Based Education Research (TIER) at the University of Maastricht, and the seminar participants at the Université libre de Bruxelles (ULB). We also thank Dan Anderberg, Emilia Del Bono, Marco Francesconi, Kjell Salvanes, Philip Verwimp and Francois Rycx for useful comments and suggestions. Jonathan James thanks the British Academy for the grant No. SG120143. 


\section{Introduction}

Teenage fertility rates in the United Kingdom (UK) are the highest in the European Union (EU), and second only to the United States (US) in the developed world. ${ }^{1}$ It is a significant policy target to reduce the number of births to teenagers because of the negative consequences of teenage births both for the effects on the child and the mother (Chevalier and Viitanen, 2003; Francesconi, 2008). Not only are there costs to the individual but also costs to the National Health Service (NHS). For example, it is estimated that teenage pregnancy costs the NHS £63 million per year. ${ }^{2}$ What has been examined less for the $\mathrm{UK}$, is the role that education can play in reducing teen births and postponing fertility.

The causal impact of education has been found to have resulted in large private labour market returns (Harmon and Walker, 1995; Oreopoulos, 2006). It is also the case that there are social outcomes that result from a more educated population, such as reductions in crime (Lochner and Moretti, 2004, for the US, and Machin et al., 2011, 2012, for the UK), enhanced political engagement and attitudes in democracy (Milligan et al., 2004; Dee, 2004), improvements in health through reduced mortality (Lleras-Muney, 2005), and better lifestyle behaviours such as more exercise (Park and Kang, 2008). Timing of fertility is another potential area in which improvement in education could have a further positive spillover effect.

There has been a number of policy interventions in the UK aimed at reducing teenage fertility and improving child health, including the teen pregnancy unit, ${ }^{3}$ and the health in pregnancy grant. ${ }^{4}$ The other side of the policy, other than direct prevention, is to cure the possible detrimental effects of teen pregnancy by helping mothers during pregnancy, and once the child has been born. Education is in the policy framework but it is typically focused on getting teenage parents back into education. The focus here is on that potential impact of improving education as a method to prevent teen fertility and postpone first birth, rather than directly tackling the problem once it has occurred. For example, Kearney and Levine (2012), while focusing on the US, find that the lack of opportunity and being on a low economic trajectory is the cause of teen childbearing, and that the lack of the chance of advancement prevents the investment in teen human capital.

\footnotetext{
${ }^{1}$ UNICEF, "A league table of teenage births in rich nations", Innocenti Report Card No.3, July 2001. UNICEF Innocenti Research Centre, Florence.

${ }^{2}$ http://tinyurl.com/teen-pregnancy-costs

${ }^{3}$ The teen pregnancy unit was set up in 1999 with a target of reducing the level of teenage pregnancy by half by reducing the probability of social exclusion through increasing education participation and labour market prospects

${ }^{4}$ Introduced in April 2009, the Health in Pregnancy grant gave pregnant women $£ 200$ to encourage healthy eating.
} 
Conceptually there are two main channels through which education could reduce a birth at an early age, and these are somewhat analogous to the education and crime literature: (1) a human capital (Black et al., 2008) or income effect (Lochner, 2004); and (2) an incarceration effect (Black et al., 2008).

In the human capital effect explanation, increases in the level of human capital for women result in having a child at an early age much more costly. Higher education levels increases future wages thereby increasing the opportunity cost of teenage pregnancy. Exam and/or curriculum changes may also have similar effects, if not just the quantity of education but also the quality is important (for example, through improvements in human capital; attained education might be more appropriate for the current labour market and the needs of society; there could be relevant signalling effects - Arrow, 1973; Spence, 1973). There are also relevant 'knowledge' effects of prolonged schooling, which give young women (through school material, Internet, and libraries) increased access to information such as family planning and contraception (Thomas et al., 1991). If these mechanisms are in place, a successful educational change should then lead to a reduction in teenage pregnancy.

In the incarceration effect mechanism it is argued that keeping young women at school increases the cost of being a mother whilst at school, and therefore may lead not necessarily to overall changes in fertility behaviour, but instead to a postponement of fertility. The schooling reforms affect not only women but also men, and hence potential fathers, extending this argument further. There could also be an impact on assortative mating, which could reduce teen fertility and marriage rates at an early age.

Previous literature which shows causal relationship between education and teenage pregnancy, mostly relying on compulsory school leaving reforms, generally show that education reduces teenage pregnancy and postpones motherhood, but the effect of education on total fertility remains ambiguous (Fort et al., 2014). In comparison to older mothers, teen mothers have lower labour market participation and are more likely to experience unemployment, have reduced schooling, are more likely to partner with men who are poorly qualified, have higher chances of post-natal depression and a higher risk of poor mental health after the birth, have higher infant mortality rates, and a greater susceptibility to riskier behaviours, such as smoking throughout pregnancy or crime involvement. At the same time, there are also risks involved in having a child post 35, such as infertility and miscarriage, premature delivery and stillbirth, gestational diabetes, bleeding complications, emergency Caesarean, etc. (Jolly et al., 2000).

Several empirical approaches have been used in order to estimate the causal effect of 
education on the reduction of teenage pregnancies and postponement of fertility. The most common identification approach is the instrumental variables (IV) approach which uses compulsory school leaving age laws as an instrument for education (Black et al., 2008; Monstad et al., 2008; León, 2004; Silles, 2011; Wilson, 2012; Geruso and Royer, 2014; Fort et al., 2014; Cygan-Rehm and Maeder, 2013; Kidar et al., 2009). Further examples include variation in the years of education based on the date of birth (McCrary and Royer, 2011) or the timing of school construction (Breirova and Duflo, 2004; Osili and Long, 2008), variation in the content of education by prolonging vocational tracks in the upper secondary school (Gronqvist and Hall, 2013), or variation in the costs of education by providing a free uniform (Duflo et al., 2011). Other approaches also include within-sibling (twin) fixed effects (Vikesh and Behrman, 2014; Geronimus and Koreman, 1992; Grogger and Bronars, 1993), instrumentation of age at first birth by age at menarche (Ribar, 1994), and miscarriage as an instrument for teenage mothers (Hotz et al., 2005). Most closely related to our paper is the identification approach which uses compulsory school leaving age laws as an instrument for education. Using the changes in the compulsory school leaving age laws in the 1960s and 1970s, previous studies for the UK show that that increased schooling does appear to reduce the incidence of teenage childbearing and postpones fertility from the early teen years to the late teens and early twenties, and that the effects of schooling are larger following the greater availability of contraception (Silles (2011); Wilson (2012)).

We examine the effect of education on the timing of fertility. In addition this paper examines the impact of, not only years of schooling, but also the importance of qualifications, and the role they can play in reducing the probability of a teen birth. We further focus not just on teen births but also examine the extent to which fertility is delayed. In order to illustrate this, we exploit two natural experiments in England and Wales.

First, we use a feature of the schooling system that led some individuals, due to their month of birth, to be able to leave the school before taking the final high school exams, and so could leave without having a qualification - the Easter Leaving Rule (ELR). The ELR determined exactly when in the school year people could leave school. Depending on their birthday, children faced one of the two possible leaving dates, the end of the Easter term or the end of the summer term. Specifically, those born between the 1st September and the 31st January could leave at Easter while those born between the 1st February and the 31st August had to stay until the end of the summer, enabling them to take end of that year exams, typically held in May and June. Dickson and Smith (2011) show that after the minimum school leaving age rose to 16 in 1973, the age at which the first set of 
high stakes exams is typically taken in the UK, late leavers were significantly more likely to obtain academic qualifications.

Second, we examine the effect of a rapid increase in post-compulsory schooling. The second reform was a combination of changes in policies that led to a large expansion in education in the late 1980s and early 1990s, which significantly raised education levels across the whole education distribution, thereby considerably reducing the number of individuals with low education levels in birth cohorts exposed to the expansion. Our approach is to think of these cohorts as a 'treated' set of individuals whose education was raised and we can compare their education and the timing first birth with a 'control' set of cohorts who did not benefit from the expansion. Overall, the proportion of 18 year olds in full time education rose from around $17 \%$ in 1985 to over $35 \%$ in the late 1990 s. Further, the proportion of women with a college degree increased from $13 \%$ to $30 \%$ from the late 1980s to the early 1990s (Walker and Zhu (2008)). We call this period of change the education expansion (EE).

This is the first paper that utilises the Easter Leaving Rule (ELR) and the large expansion of the UK post-compulsory education system (or Education Expansion (EE)) that occurred in the late 1980s and early 1990s in order to investigate the relationship between education and fertility timing. We use regression discontinuity difference-indifferences (RD-DD) and instrumental variables (IV) estimation approaches to show that the improvements in qualifications as a result of the ELR and the raise in education levels as a result of the EE did not lead to a reduction in the probability of having a child as a teenager. However, we do find that both sources of variation in education led to delays in having a first child. There is no evidence that the mechanism driving these findings are due to an incapacitation effect. Instead the results point to both a direct human capital effect and an improvement in labour market opportunities as a result of holding qualifications.

The remainder of the paper is organised as follows. Section 2 provides the institutional setting for the Easter leaving rule and the expansion of the UK post-compulsory education, while Section 3 outlines the empirical strategy. Section 4 describes the data utilised in the paper, and Section 5 provides the estimation results and the robustness checks. Section 6 concludes this paper. 


\section{Institutional Setting: The Easter Leaving Rule and The Expansion of The UK Post-Compulsory Edu- cation}

\subsection{The Easter Leaving Rule}

Across England and Wales there are five stages of education: early years foundation stage (ages 3-5), primary education (ages 5-11), secondary education (ages 11-16), Further Education (FE) (ages 16-18) and Higher Education (HE) (ages 18+). Education is compulsory for all children between the ages of 5 and 16, up to and including secondary education. Children start school in the academic year in which they turn 5, and the academic year runs from the 1st September to the 31st August. Historically, in response to the need of a more educated workforce post-war, the compulsory school-leaving age was raised to 15 in 1947, and to 16 in 1973. Since the Education Act of 1962 and up until 1997, the ELR determined exactly when in the school year people could leave school. Depending on their birthday, children faced one of the two possible leaving dates - the end of the Easter term or the end of the summer term. Specifically, those born between the 1st September and the 31st January could leave school at the end of the spring term (i.e., just before Easter), while those born between the 1st February and the 31st August had to stay until the Friday before the last Monday in May (i.e., the end of the summer term), enabling them to take end of that year exams, typically held in May and June. From 1998 onwards, a new single school-leaving date was set as the last Friday in June in the school year in which the child reaches the age of 16. In order to exploit the ELR identification strategy, the academic cohorts of women who are in the focus of our study are divided into two groups: the women who were born in the period September-January who were allowed to leave school at Easter, and the women who were born in the period February-August who were required to stay on at school until the end of the academic year. This generated a within-cohort threshold, implying a nominal difference of up to two months (roughly equal to one academic term) of required schooling, but also enabling the February-August group to take high-stakes exit examinations at the end of the school year and gain academic qualifications.

Dickson and Smith (2011) show that after the minimum school leaving age rose to 16 in 1973, the age at which the first set of high stakes exams is typically taken in the UK, late leavers were significantly more likely to obtain academic qualifications. Del Bono and Galindo-Rueda (2007) go one step further and show that the ELR had not only a 
strong impact on qualifications achieved by age 16, but also on adult educational outcomes. Further, completing a year of education in which individuals can be awarded nationally recognized qualifications, has significant positive effects on later labour market participation, employment, and earnings. Del Bono and Galindo-Rueda (2007) confirm the conventional findings that formal education is a more important driver of employment and participations decisions for women than it is for men, which is relevant for the interpretation of findings in our paper.

Using the ELR as an identification strategy, Anderberg and Zhu (2014) show that women who were required to stay on an extra term more frequently hold some academic qualifications, which subsequently had no effect on the probability of being currently married for women aged 25 or above, but increases the probability of the husband holding some academic qualifications and being economically active. Using the same identification approach, Braakmann (2011) shows that obtaining any sort of educational qualifications indicates neither an effect of education on various health related measures nor an effect on health related behaviour, e.g., smoking, drinking or eating various types of food. The proposed explanation is that those who comply with the ELR and are essentially 'nudged' into gaining qualifications, apparently do not enjoy a labour market advantage over individuals without qualifications, and hence they also do not have better health outcomes.

\subsection{The Expansion of UK Post-Compulsory Education}

In the UK the proportion of 18 year olds in full time education has rapidly expanded in the late 1980s and early 1990s. Figure 1 shows the rapid increase in participation over the analysed period, represented by a significant step change. Overall, the proportion of 18 year olds in full time education rose from around $17 \%$ in 1985 to over $35 \%$ in the late 1990s. The expansion raised education levels across the whole education distribution. Figure 1 also shows that the rise occurred for both further education, i.e., post-compulsory schooling (the minimum school-leaving age law in place at the time prohibited leaving school before 16), and higher education. For both measures there was over a doubling in participation over the period. Walker and Zhu (2008) further show that the proportion of women with a college degree increased from $13 \%$ to $30 \%$ from the late 1980 s to the early 1990s.

There were two main causes for the rapid rise in education over the analysed period. First, there was a significant change in the high school exam system. Second, there were significant changes in the supply of higher education. 
For the expansion of the post-compulsory sector through increased staying on rates, Blanden and Machin (2004) highlight the change in the school leaving examination system that took place in 1988, with the introduction of the General Certificate of Secondary Education (GCSE) and the consequent improvement in examination results. The General Certificate of Secondary Education (GCSE) combined the O-level (General Certificate of Education (GCE)), a higher tier exam, and the Certificate of Secondary Education (CSE), a lower tier exam. These changes led to an improvement in results, which may have encouraged people to stay on into further and higher education. There were two main reasons why this exam change may have led to an improvement in attainment. First, a cap on the number of people who could receive a specific grade was removed. Therefore, more students could achieve grades $\mathrm{A}$ to $\mathrm{C}$ which are considered to be passing grades. This move from norm-reference exams, which placed emphasis on relative performance, to criterion-referenced assessment meant that it was possible for everyone to get the top grades (Blanden et al. (2003)). Second, there was a move away from the assessment being based just on exam performance to include a sizeable element of coursework.

Gray et al. (1993) show that the most important determinant in predicting post-16 schooling were the received qualifications. Gray et al. (1993) also provide evidence that there were big jumps in attainment. Using the Youth Cohort Study (YCS) they find that while only $30 \%$ of students obtained 4 or more high grade passes in 1986 (pre-GCSE), this increased to $40 \%$ in 1988 - the first year of the GCSE. There was an increase at almost every level. Therefore someone born in 1972 and after who had the same ability and other characteristics (such as, for example, a similar discount rate) would have had a greater opportunity to stay on in education due to the change in the examination system as they would have achieved the grades that would have allowed them to go on to further study, than someone born before 1972 .

Further, changes to the structure of the economy, moving away from manufacturing and into services and the perceived increases in returns to education was also another significant driver of this increase in education demand, see Blanden and Machin (2004), Kogan and Hanney (2000), Devereux and Fan (2011).

In addition to the changes in the high school exam system, there were changes to the supply of university places. There were two key features that lead to the rise. Blanden and Machin (2004) and Walker and Zhu (2008) discuss increased university enrolment in the light of changes in admissions and in financing. There was a relaxation in the limits of student places, but also the per university student government grant financing was abandoned, and as a result this increased the incentives for the universities to enrol 
more students. The Further and Higher Education Act 1992 also lead to an expansion of university education as many polytechnic institutions became universities, the main difference between the two institutions being that universities could award their own degrees.

The education expansion effects that are examined in this paper are therefore a combination of both policy changes (i.e., changes in the high school exam system and changes in the supply of higher education). They do interact with each other and did not have independent effect on the education distribution. Alone, the exam changes would have had an impact at the bottom of the education distribution. However, with the expansion in higher education occuring in conjuction with the changes to exam system, high school students were in a position to take advantage by staying in school longer and then moving into higher education. Devereux and Fan (2008) point out that the improvement in grades would have led to students believing they were good enough to go on to higher education.

A rapid increase in post-compulsory schooling in the UK in the late 1980s and early 1990s has already been used as a source of identification in other areas. Blanden and Machin (2004) study focuses on the education expansion as a key driver of falling intergenerational mobility. Devereux and Fan (2011) have also looked at wage effects associated with the education expansion, showing that on average it caused men and women to gain respectively a year or slightly more than a year of education and that this significantly raised wages. Machin et al. (2012) show that the education expansion reduced both male and female youth crime rates, while James (2015) looks at the effects of education expansion on a range of health outcomes finding significant reductions in body size. ${ }^{5}$

\section{Empirical Strategy}

\subsection{The ELR Empirical Strategy}

The Easter Leaving Rule (ELR) was an institutional feature that generated two possible school leaving dates, such that those born between the 1st September and the 31st

\footnotetext{
${ }^{5}$ Other related literature, which similarly exploit 'indirect effects' of the education polices, are the papers by Maurin and McNally (2008) and Nordin (2014). Maurin and McNally (2008) show that the May 1968 student riots in France resulted in abandonment of normal examination procedures and an increase in the pass rate for various qualifications. The lowering of exam thresholds enabled a proportion of students to pursue more years of higher education than would otherwise have been possible, which subsequently increased wages and occupational levels of the affected cohorts, and has transmitted across generations into better education performance of their children. Nordin (2014) shows that after a change to a goal- and criterion-referenced grading system in Sweden in 1994, there was a substantial grade inflation, which increased the tertiary education eligibility, and resulted in the crime reduction of the affected cohorts.
} 
January could leave school at the end of the Easter term in the academic year in which they reach the school leaving age (15 before 1973, and 16 following the 1973 reform). Those born between the 1st February and the 31st August had to stay in school longer, until the end of the summer, when they reached the school leaving age. Taking end of that year exams, these late leavers were significantly more likely to obtain nationally recognized academic qualifications (the General Certificate of Education Ordinary Level (GCE O-level), obtained by the secondary school students who were more academically oriented, and the Certificate of Secondary Education (CSE), obtained by less academically oriented students, when compared to early leavers; these two were merged into the General Certificate of Secondary Education (GCSE) after 1988).

The institutional feature which induced two possible school leaving dates generated a discontinuity point at 31st January/1st February - children born at either side of the discontinuity start education at approximately the same age, are in the same school cohort, and have approximately the same level of maturity within a cohort. Therefore children born at either side of the discontinuity point are identical with respect to their unobserved characteristics, such that the institutional rules which imposed at which point they are allowed to leave the compulsory schooling are the only source of difference in their educational qualifications. This 31st January-1st February discontinuity can therefore be exploited in a regression discontinuity (RD) framework. We define ELR as a dummy variable indicating whether the individual has to stay on at school such that they take the high school exams.

$$
E L R_{i}= \begin{cases}1, & \text { if } M o b_{i}=2, \ldots, 8 \\ 0, & \text { otherwise }\end{cases}
$$

where $M o b$ indicates month of birth. The standard regression discontinuity framework can therefore be represented by the following reduced form regression:

$$
F_{i}=\gamma_{0}+\gamma_{1} E L R_{i}+f\left(M o b_{i}-c\right)+\lambda X_{i}+\nu_{i}
$$

where $F_{i}$ is a measure of timing of fertility (age at first pregnancy; probability of becoming a teen mother; probability of delaying pregnancy) for individual $i, f\left(M o b_{i}-c\right)$ is a flexible polynomial of month of birth that is centered around the cut-off, $X_{i}$ is a vector of control variables (age, age squared, non-white, living in London, birth cohort dummies, year of survey dummies) and $\nu_{i}$ is an error term. The discontinuity in this case is not sharp so we specify a the following first stage reduced form equation: 


$$
Q_{i}=\beta_{0}+\beta_{1} E L R_{i}+f\left(M o b_{i}-c\right)+\delta X_{i}+\varepsilon_{i}
$$

where $Q_{i}$ indicates whether the woman has any academic qualifications. The underlying assumption is that assignment to either side of the discontinuity is random. Therefore those who are above the threshold are the treated group and those below are the control group. While this is probably a reasonable assumption as one gets closer and closer to the cut-off, it is less likely to hold the further away from the cut-off one gets. Recent evidence has pointed to the possibility that individuals born at different times of the year are born to mothers with significantly different characteristics. Buckles and Hungerman (2013) document for the US that those born in the winter are more likely to have a mother who is a teenager, are less likely to be married and are less likely to have a high school diploma.

Given this possible threat to our identification strategy we employ a regression discontinuity difference-in-difference (RD-DD) estimation approach, as introduced by Danzer and Lavy (2013). We are able to do this as the ELR we describe only had bite after the raising of the school leaving age (RoSLA) to sixteen. Therefore, we are able to introduce an additional control group that will allow us to take into account any seasonal effects that may be present. Our treated group are therefore those born after February (to August), born in the post RoSLA period. We therefore estimate the following set of equations:

$$
\begin{aligned}
& Q_{i}=\beta_{0}+\beta_{1} E L R_{i}+\beta_{2} \operatorname{RoSLA} A_{i}+\beta_{3} E L R_{i} \times R o S L A_{i}+X_{i} \delta+f(M o b-c)+\varepsilon_{i} \\
& F_{i}=\gamma_{0}+\gamma_{1} E L R_{i}+\gamma_{2} \operatorname{RoSLA} A_{i}+\gamma_{3} E L R_{i} \times \operatorname{RoSLA}_{i}+X_{i} \lambda+f(M o b-c)+\nu_{i}
\end{aligned}
$$

In addition to the RD-DD estimation given by $\gamma_{3}$ we also estimate the effect of qualification using an instrumental variable (2SLS) approach using $E L R_{i} \times R o S L A_{i}$ as our excluded instrument. The interpretation of this estimate is a local average treatment effect (LATE), that is, the estimated effect is for those who obtained educational qualifications induced by the institutional rule (the "compliers"). We further estimate specifications that allow the month of birth function $f(M o b-c)$ to differ on either side of the ELR discontinuity by including an additional interaction term $E L R \times f(M o b-c)$.

A potential threat to the identification could again be that those in our treated group (i.e., those who are subject to the ELR after the RoSLA) may have different family background characteristics relative to the control group, thus invalidating the exogeneity condition of the ELR-RoSLA interaction term as an instrument. As a check of our identification strategy we use data from the first wave of the Understanding Society data 
set $^{6}$. The data contains information on the qualifications of the mother and the father. We classify four categories of education separately for the mother and the father: (i) having a degree or a higher degree; (ii) in addition to the first category, we also include having post-school qualifications or certificates; (iii) this group indicates whether the mother or the father left school with some qualifications or above (i.e., we also include category i and ii); and (iv) whether either the father or the mother left without any qualifications or did not go to school at all. The estimation mimics what we do in the reduced form estimation in equations (3) and (4) but replaces the individual qualifications with that of the father or the mother. This is documented in Table A4 in Appendix. For both the RD, RD-DD and RD-DD with a quadratic spline we do not find any systematic differences in family background characteristics between those who were subject to the ELR (RD), or those subjected to the ELR after the RoSLA (RD-DD). This evidence therefore supports our empirical strategy.

\subsection{The EE Empirical Strategy}

To examine the effect of the education expansion we begin by presenting the first stage showing the relationship between the education expansion cohorts and educational achievements:

$$
E d_{i c}=\alpha+\sum_{c=1972}^{1975} \beta_{c} \text { Cohort }_{c}+\delta \text { After }_{c}+f\left(\text { Age }_{i c}\right)+g\left(\text { Cohort }_{c}\right)+\varepsilon_{i c}
$$

We also estimate the following reduced form regression:

$$
F_{i c}=\phi+\sum_{c=1972}^{1975} \gamma_{c} \text { Cohort }_{c}+\lambda \text { After }_{c}+h\left(\text { Age }_{i c}\right)+k\left(\text { Cohort }_{c}\right)+\omega_{i c}
$$

where the $i$ subscript denotes individuals, and the $c$ subscript denotes cohorts; $\varepsilon$ and $\omega$ are equation error terms. $E d$ is a measure of completed education, $F$ is a measure of timing of fertility (age at first pregnancy; probability of becoming a teen mother; probability of delaying pregnancy), Cohort denotes the education expansion cohorts (dummy variables), After is a dummy variable which picks up the effect of post-expansion cohort. The omitted category is the pre-expansion cohort. The coefficients on the Cohort dummies show the increase in education of each cohort relative to the average education level of

\footnotetext{
${ }^{6}$ Given that we are interested in the family background (specifically the education level of the parents) we only use one wave (the first) of Understanding Society as these are assumed to be completed and will unlikely change over time
} 
the pre-expansion cohorts. The functions of Age and Cohort include a quadratic effect in cohort and a cubic effect in age. ${ }^{7}$ In this way, the cohort dummies do not pick up any trend increases in education, just that part of the increase in education that deviates from the underlying trend.

The identification strategy relies on examining cohort-level changes in education and a number of fertility-timing outcomes. This identification strategy follows the methodology of Devereux and Fan (2011) who have looked at wage effects associated with the education expansion, showing that on average it caused men and women to gain respectively a year or slightly more than a year of education and that this significantly raised wages. Machin et al. (2012) used the same identification strategy to show that the education expansion reduced both male and female youth crime rates, while James (2014) looked at the effects of education expansion on a range of health outcomes finding significant reductions in body size.

A nice feature of the reform in question is that it affected the entire education distribution. Unfortunately, however, this means that it is not feasible to use a portion of the cohort not affected as a control group, as in Etilé and Jones (2011). Additionally, during this period of expansion, Scotland also experienced expansion in the higher education sector, and hence does not make a feasible control group. The strategy employed therefore rests on identifying changes in the cohort trend that cannot be captured using a low-order cohort polynomial. Therefore there may be underlying differences from cohort to cohort in fertility-timing behaviours, however, there is no reason to think that the other factors that influence fertility-timing do not change smoothly, and would therefore be captured by the cohort trends.

Using equations (6) and (7), we can estimate the Two Stage Least Squares Regressions (2SLS), giving us the (social) return to education in terms of timing of fertility. The coefficient of interest is the effect of education on fertility timing measured by age at first pregnancy, probability of becoming a teen mother, and probability of delaying pregnancy. The interpretation of this estimate, under the assumption of monotonicity, is a local average treatment effect (LATE), i.e., the estimated effect is for those who obtained more education as a result of the expansion. In contrast to changes to compulsory schooling which exclusively affect the bottom end of the distribution, this reform is for a broader

\footnotetext{
${ }^{7}$ While this is not strictly a regression discontinuity design (RDD), it has a similar flavour. Gelman and Imbens (2014) point out that high order polynomials should not be used in RDDs. In any case, we test the robustness of the 2SLS estimates to the specification of both the "running variable" (birth cohort) and how age is put into the model. In Figures A3-A5, bars 9, 10, 11 include age quartic, year of birth cubic, and then both age quartic and year of birth cubic. The results appear robust to these alternative specifications.
} 
part of the population, however, the interpretation remains the same in that the effect is for the compliers of the reform.

The validity of the instruments in this case rests on the assumption that the education expansion cohorts significantly explain the variation in education without being correlated with unobservable characteristics that are correlated with education and fertility timing such as family background, risk aversion, or time preference. Table 2 explicitly tests the first requirement. The second requirement entails that the expansion was not explicitly aimed at improving fertility timing or implemented as a reaction to more teenage pregnancies. There is no evidence that this is the case. For example, the Further and Higher Education Act does not explicitly mention fertility-timing outcomes as a reason for the changes either directly or indirectly. ${ }^{8}$

The key identifying assumption in using the set of cohort dummies as instruments for education is that the conditional expectation of the fertility timing outcomes with respect to the birth cohort is that in the absence of the education expansion, the changes could be explained by a low-order cohort polynomial. Therefore, one way in which we can indirectly test this assumption is by examining the effect of the instruments (cohort dummies) on pre-determined or background characteristics. To do this, as we presented in the previous section for the ELR, we use the first wave of the Understanding Society data set. The idea here is to examine whether there is a systematic difference in the background characteristics of those individuals who were affected by the education expansion. If there is then this suggests that what we find might be driven by difference in background characteristics rather than differences in education. Table A5 in Appendix 6 presents the results of this exercise. We do not find any differences in parental education for the EE cohorts. None of the forty coefficients are significant and neither are any of the joint tests of the EE cohort dummies and the post EE indicator.

\section{Data and Descriptive Figures}

We use the Labour Force Survey (LFS) in the period from 1975 to 2013. The LFS is a Great Britain household survey covering around 60,000 households, responding each quarter. It is a rotating panel where households are surveyed for five successive quarters. One fifth of the households are undertaking their first interview in each quarter. One fifth of the sample are taking their second interview and so on. The LFS contains information regarding education, including age at which full-time education was completed, as well as

\footnotetext{
${ }^{8}$ Further and Higher Education Act 1992:

www.legislation.gov.uk/ukpga/1992/13/pdfs/ukpga_19920013_en.pdf
} 
highest education qualification achieved. In order to assign individuals to school cohorts, we used month of birth - individuals born in the first three quarters of a year were assigned to the first school cohort in which they were eligible to start school (i.e., the first academic term following their fifth birthday); individuals born in the last quarter of a year were assigned to the next school cohort.

The LFS provides the necessary information on each individual's year and month of birth in addition to their highest educational qualifications, age when completed fulltime education, as well as their labour market status. For each individual, we only use information when she first appeared in the data.

Similar to Black et al. (2008) analysis for the US and Wilson (2012) analysis for the UK, age at motherhood is determined from the ages of the mother and the eldest child within a household at the time of the survey. This procedure assumes that a mother-child relationship can be observed only if both individuals are present in the same household at the time of the survey. Allowing for parental separation, this approach assumes that the child is resident with the mother, so that the observed mother-child relationship is biological. Further, this approach also assumes away child mortality. Although parental separation and child mortality may induce measurement error, it is likely that any effect would be small, because in the case of parental separation, a child usually stays with the mother, and the childhood mortality rates have been declining over time. ${ }^{9}$

Figure 2 shows the effect of the institutional feature which induced two possible school leaving dates generating a discontinuity point at 31st January/1st February, pre-RoSLA (left-panel) and post-RoSLA (right-panel). There is a jump in the proportion holding qualifications in the post-RoSLA period, after the minimum school leaving age rose to 16 in 1973, the age at which the first set of high stakes exams is typically taken in the UK. In the pre-RoSLA period such a jump is not apparent.

Figures 3 and 4 represent the mean of the timing of fertility outcome by month of birth, similarly to figure 2 , separated into two time periods: pre-RoSLA and post-RoSLA. The lines are non-parametrically fitted using a triangle kernel with a bandwidth of three (see also Carneiro et al. (2013)). Figure 3 shows the results for births before aged 21 (left panel) and after aged 24 (right panel). If a January-February discontinuity is present in the post-RoSLA period it appears to be matched by a discontinuity in the pre-RoSLA period. This highlights the importance of our RD-DD approach. Figure 4 presents the means and non-parametric fit for births after the age of 26 and 30. In the post-RoSLA

\footnotetext{
${ }^{9}$ We assume that a potential measurement error in the dependent variable has zero mean; if it does not, then we simply get a biased estimator of the intercept, which is not be of a big concern, Wooldridge (2009).
} 
period there is a distinct January-February discontinuity which is not matched in the pre-RoSLA period. This graphically shows that there was increase in delaying fertility for those born in February relative to January in the period after the school leaving age was raised.

Figures 5 and 6 show how education changed by cohort. In order to control for any age effects and a potential secular trend in education, similar to Ichino and WinterEbmer (2004) we calculate residuals from fitting a polynomial in age up to a cubic. ${ }^{10}$ Figure 5 presents age left full-time education and having a degree education measures after controlling for a cubic age profile. The area in between the two vertical lines represents the cohorts from 1972 to 1975 which were affected by the expansion in education. For both measures of education, the education expansion period is evidently characterized by a strong positive deviation from the secular trend. After the expansion period there is still a positive deviation from the trend, which then has leveled off for the affected cohorts. Figure 6 shows a similar pattern for the post-16 measure of education. There is a sharp, positive, and rapid deviation from the secular trend for the education expansion cohorts. For those having no qualifications, there is a downward trend occurring before the expansion period and carrying on through the expansion period.

Turning to the the timing of fertility measures, Figure 7 presents the residuals of the probability of birth before age of 21 , while Figure 8 presents the residuals of the probability of birth after age of 21 , both after controlling for a cubic age profile. For women younger than 21, throughout the EE period we do not see a deviation away from the secular trend, but there is a slight increase after the expansion. We will test to see whether this deviation is significant in Section 5. In contrast, we do see significant positive deviation in the trend when we examine births after being 21 years old. There is no deviation for births to mothers age 21 and above. However, there is a sharper deviation for all ages 27 and above. For these groups the deviation is much clearer. For the post expansion cohorts there is still a positive deviation, however, this is declining. Tables A1-A3 present the descriptive statistics for the cohorts used in the EE reform.

\footnotetext{
${ }^{10}$ We have tried controlling for quartic, quadratic, and linear polynomials in age, as well as no controls, and we find a similar pattern of results as those presented in the paper.
} 


\section{Results}

\subsection{The Effect of the ELR and EE on Education Outcomes}

Table 1 shows the first stage estimates for the ELR reform. In columns (1) and (2) we regress holding any qualifications on an indicator for whether an individual was subject to the ELR pre- (column (2)) and post-RoSLA (column (1)). Someone born in February to August was 4.5 percentage points more likely to hold qualifications relative to someone born in September to January in the post-RoSLA period. In column (2), as in column (1), we do not restrict the sample by month of birth but instead estimate the effect on qualifications for the pre-RoSLA period only. We do not find any impact of the ELR in this pre-RoSLA period. In columns (3) to (8) we estimate our preferred RD-DD specification. Our estimates of the effect of the ELR on qualifications using this specification range from 3 to 3.86 percentage points with $F$-statistics all above 10, out of the six estimates four are above 40. Comparing columns (4) and (5) shows that the introduction of the quadratic spline does not dramatically alter the effect.

Table 2 shows the first stage estimates for the EE reform, for four different measures of education. In the first column we show age in which one left full-time schooling, the second column shows age left full-time education after compulsory leaving age (i.e., after age 16). In the next column we show the effect of the expansion on achieving a degree, and finally we present whether someone has no qualifications. We include a set of dummies for each of the 1972 to 1975 inclusive cohorts in order to represent the expansion in education. As shown in the figures in Section 6, these were the years where the expansion was at its most rapid. We also include a dummy representing the post expansion cohort, therefore, the estimates we find are relative to the cohorts who experienced the pre-GCSE exam system.

For all of the measures of education there is an increase for each of the cohorts, with each subsequent cohort being greater than the previous. For age left full-time education, the significant step-change monotonically increases. The coefficient on the 1972 cohort is 0.181 , this increases to 0.788 for the 1975 cohort, with the post-expansion dummy coefficient being 0.952 . The pattern is similar for staying on past 16, with the cohort coefficients increasing from 0.026 in 1972 to 0.161 in 1975 , with a plateau at 0.242 in the period post education expansion. There are also improvements for those achieving a degree. The pattern is similar to the other two measures of education. For those holding no qualifications we see a fall. This fall is predominantly in the latter part of the expansion period. The $F$-statistic for the joint test of the 1972 to 1975 cohorts is not as 
large as compared to age left school or leaving education after 16 . The $F$-tests for age left education, post-16 and degree are all above 10 . For having no qualifications, the $F$-test is significant but not above 10 .

\subsection{The Effect of the ELR and EE on Fertility Timing}

Table 3 presents the reduced form effects of the ELR and EE reforms on the age of first birth and then subsequently on whether a birth occurred before a certain age. We consider births before 16 up to births before 21. All of these births would be considered to be teen births. Panel A presents the results from the ELR. Two specifications are presented, with and without a quadratic spline. We do not find any evidence that the ELR had an effect on the age at first birth or on the probability of a teen birth.

Panel B presents the results from the EE reforms. The first column shows an increase in the age of first birth for the EE cohorts. Those born in 1973 had a child just under a third of a year later relative to the pre-expansion cohorts. This increases to just over half a year for the post-education expansion cohorts. The $F$-statistic of the joint test of the 1972 to 1975 cohorts is only significant at the $10 \%$ level. We do not find much evidence that this increase in the age of first birth was as a result of fewer women having children as a teen. Other than having a child before the age of 18 , all of the $p$-values of the $F$-statistics testing the joint significance of the cohort dummies are insignificant. Furthermore, the point estimates on the cohort dummies do not reveal a pattern that suggests a decline in the probability of a teen birth.

In Table 4 we consider whether the ELR and the EE reforms led to a delay in fertility. We begin by examining births after age 21 up to after the age of 30. Panel A shows the effects on delaying fertility for those affected by the ELR. Using the specification without a quadratic spline, we find that the ELR increased the probability of a birth after the ages of 26 by 1.1 percentage points; this increases to 1.8 percentage points for those aged 30 and above. The estimates including a quadratic spline are of a very similar magnitude.

For the EE reform, presented in panel B, there is little evidence that there was a delay in fertility up to age 26. However, when we consider the probability of births for those aged 27 or above, we then find that the education expansion cohorts are more likely to have births after this age. This occurs mainly for the 1973 to 1975 cohorts, and we do not see a significant effect for the 1972 cohort. This reflects that the 1972 cohort was the least affected by the education expansion. Caused by the education expansion, we estimate an increase in the probability of a birth when aged 28 or above by 4 percentage points for the cohort born in 1975. Similar estimates are found for the probability of a 
birth when aged 29 or above, and 30 or above. The $F$-statistics in columns (7) to (10) all suggest the joint significance of the 1972 to 1975, and the post-education expansion cohorts dummies.

Therefore to summarize, we find a significant effect on delaying fertility as a result of the ELR and the EE reforms. We do not find those affected by the ELR less likely to become teen mothers. By the end of the EE period, those in the post-expansion cohorts were around half a year older when they had their first child relative to the pre-expansion cohorts. This increase in the age of first birth is not reflected in a reduction in the probability of a birth by a teenager. Instead, we see an increase in the delay of fertility. We see this because there is an increase in the probability of a birth after the ages of 26 for those affected by the ELR reform, and 27 for those affected by the EE reform. To a certain extent, this reflects the nature of the EE reform. As seen in Table 2, the education expansion led to more time in school but also an increase in post-compulsory schooling and obtaining a degree. Therefore, this is in line with the timing of fertility effects that we find such that they occur after a degree would have been completed.

\subsection{The Effect of Education on Fertility Timing}

Next we turn to examine the effect of education on fertility timing. Table 5 presents OLS and IV estimates for five different fertility timing measures. First is the age of first birth. Then we consider the probability of a teen birth (defined as having a first birth before the age of 21). The final three measures we use are dummy variables which indicate whether a woman had a child aged 24 or after, 27 or after, and 30 or after.

Panel A presents the results from the variation in education induced by the ELR. All specifications are based on those that include a quadratic spline. The OLS estimates imply that those with qualifications have a child 1.2 years later. The 2SLS estimate is in the opposite direction but it is not statistically significant. For the other fertility timing measures the OLS estimates show that those with qualifications are less likely to have a teen birth and more likely to delay fertility.

Panel B presents the estimates for age left full-time education from the EE. The OLS estimates suggest that leaving school one year later leads to an increase in the age of first birth by three quarters of a year. The IV estimates are somewhat lower with an effect size of half a year. One interpretation is that women have unobserved characteristics that also make them more likely to delay fertility. Controlling for these characteristics reduces the estimated effect but does not eliminate it. However, the Hausman test implies that these estimates are not significantly different from each other. 
Using the same source of identification, the OLS estimates suggest that an additional year of schooling is associated with a reduction in the probability of a teen birth by 3 percentage points. However, as was reflected in the reduced form analysis in Table 2, we do not find a significant result when we estimate the effect of education using 2SLS. Similarly when age of first birth is the dependent variable, we see a reduction in the point estimate by over $50 \%$, however it is no longer precisely estimated.

In columns (5) to (10), we examine the effect of education (for age left full-time education from the EE) on delaying fertility. In each case the 2SLS estimates is smaller than the OLS estimates. The 2SLS estimate when the dependent variable is an indicator for whether the birth occurred to a woman aged 24 or older, and 27 or older is significantly different from the OLS. These estimates suggest an additional year of schooling leads to an increase in probability of a birth aged 27 or after by 3.9 percentage points. Compared to the pre-education expansion mean, this represents a $5 \%$ increase in probability of birth 27 or above. The IV estimate for being aged 30 or above for a first birth is the equivalent of an $8 \%$ increase.

In Panels $\mathrm{C}$ and $\mathrm{D}$ we examine two alternative measures of education again using the EE reform. Panel $\mathrm{C}$ presents the results of having a degree as the margin of education. Panel D uses an indicator as to whether someone stayed on in school after the age of 16 . The OLS estimates suggest that those with a degree are almost 4 years older at the time when they have their first child than those who do not. By instrumenting education using the expansion cohorts and a post-expansion dummy, we find that this estimate increases to 5.9 years. The difference between these two estimates is not statistically significant although it is an effectual difference. The direction of the difference is in contrast to when we use age leaving full-time education as the measure of schooling. First, this could be due to measurement error. As measurement error may bias the OLS estimate towards zero it could be the case that there is more measurement error in recalling having a degree (or there may be greater misclasification as to what constitutes having a degree) compared to the age at which one left school. An alternative explanation is that the marginal effect of schooling for women affected by the education expansion may be larger than the average effect for the population, and this is particularly the case with respect to getting a degree. The estimates we find are the effect of obtaining a degree for women who would not have gotten a degree had it not been for the expansion. This is also confirmed by Del Bono and Galindo-Rueda (2007), who find that formal educational degree is a more important driver of employment and participations decisions for women that it is for men. 


\subsection{Robustness Checks and Additional Results}

We present robustness checks of the main significant results, i.e., for the following dependent variables ELR: birth after the age of 27, and birth after the age of 30. For the EE reform we examine: age of the first birth, birth after the age of 27 , and birth after the age of 30

The figures A1 and A2 in Appendix present the estimates for a first birth aged after 27 and 30, respectively. The figures show a series of robustness checks and placebo tests for the results from the ELR. Specification 1 presents the baseline estimates with quadratic spline for comparison. We check the sensitivity of the results to the specification by adding a cubic in the centred month of birth variable (specification 2), while specification 3 also includes cubic spline. This does not change the effect. Specifications 4-10 examine the effect of changing the regression specification with respect to age, and month and year

of birth. Specification 4 restricts the month of birth window from November to April, while specification 5 restricts the month of birth window from December to March. This narrowing of the window leaves the point estimate of 4 unchanged whereas specification increases slightly. The estimates of this specification become slightly less precise in both figures A1 and A2 as would be expected. Specification 6 restricts the sample to the cohorts 1940-1969, specification 7 to 1941-1969, specification 8 to 1942-1969, specification 9 to 1943-1969, while specification 10 restricts the sample to the cohorts 1944-1969. For both dependent variables the results remain virtually unchanged. In specifications $11-18$, a placebo test uses a fake month of birth $\times$ RoSLA interaction as the instrument, running from March to November. None of these placebo tests produce a statistically significant result, in both figures specification 14 gives the largest point estimate however this is insignificant. Most of our estimates are also lower than the baseline. The placebo and robustness results add confidence in our baseline estimates.

We next turn to the robustness of the results from the EE. The figures A3 - A5 in Appendix present the robustness estimates for a different specification (age at first birth Figure A3, birth after age of 27 - Figure A4, and birth after age of 30 - Figure A5), for the measure of education age left full-time education, with the corresponding $95 \%$ confidence interval. Specification 1 presents the baseline estimates for comparison. The first set of changes are designed to see how sensitive the estimates are to changing the structure of the instruments. Specification 2 excludes the post education expansion dummy as an additional instrument and this forces the identification to come from the cohorts that were effected just during the expansion years. Specifications 3 and 4 change the period of education expansion by including earlier cohorts as instruments. Specification 5 reduces 
the number of instruments by combining the expansion cohorts into one (a single dummy for the 1972-1975 cohorts), and specification 6 into two dummies (a dummy covering the 1972-1973 cohort, and one for 1974-1975 cohort). Specifications 7 to 10 revert back to the original instrument set and examine changing the specification of the age variables. In particular, specification 7 replaces the polynomials of age with a set of age dummies. Specifications 8, 9, and 10 examine the effect of changing the regression specification with respect to age and year of birth. Specification 8 presents the 2SLS estimates additionally including a cubic for year of birth. Specification 9 additionally includes a quartic in age to the baseline specification, and specification 10 presents the estimates when year of birth and age quartic are included.

Age effects on fertility may have changed over cohorts, and controlling for age may not be sufficient to control for such effects. In order to address this, specification 11 includes an age cohort interaction as an additional control, we include the square and cubic of this interaction in specification 12 and 13 in order to control for this in the most flexible way, and in specification 14 we additionally include a quartic.

However, in order to examine whether changing the age of the sample matters in specification 15 the sample is restricted to those aged 21 to 35 . The sample is restricted to include individuals born between; 1965-1979 (specification 16), 1966-1979 (specification 17), and 1967-1979 in specification 18. In specification 19 estimates are presented where limited information maximum likelihood (LIML) is used rather than 2SLS. This is because in over-identified models with weak instruments, 2SLS will be biased and this is not the case with LIML. Therefore, a comparison between the 2SLS estimates and those estimated using LIML will also serve as a test of weak instruments.

Taking the three figures together we underline two results. First, the baseline estimates are not significantly different than the range of estimates presented that adopt a number of different instrument sets and specifications. Second, the inclusion of age cohort interactions cause the estimates to fall a little, although this difference is not statistically significantly different from the baseline estimate. For the dependent variable of age of first birth, the inclusion of age cohort up to a quadratic does not significantly change the point estimate, however, it does make the estimate less precise. For the dependent variable age of birth after 27, we find that a flexible specification which includes a quadratic of this age cohort interaction (specification 14) results in a significant result, but less flexible specifications lead to imprecise estimates. When we use age of first birth being above 30, all our estimates remain statistically significant. 


\section{Conclusion}

In this paper we have documented the effect of two sources of variation in education. The first was an institutional feature that generated two possible school leaving dates, such that those born between the 1st September and the 31st January could leave school at Easter, while those born between the 1st February and the 31st August had to stay in school until the end of the summer. Taking end of that year exams, these late leavers were significantly more likely to obtain academic qualifications. Despite the increase in qualifications, we find no evidence that this institutional feature led to a reduction in the probability of being a teen mother. However, we find an increase in the probability that births after the age of 24 increased, hence there was a delay in fertility. Similarly, the EE reform resulted in large increases in post-compulsory schooling participation. This led to increases in age of first birth. Similar to the results from the ELR, we find that an increase in education, either through an increase in age finishing full-time education or obtaining a degree, led to delaying fertility. Our estimate suggest an increase in education by one year led to a $5 \%$ increase in probability of birth when aged 27 or above.

Based on our findings, we are able to consider two effects that could explain the relationship between education and the timing of fertility. The body of evidence points to the effect of education on fertility being driven by a combination of human capital and incapacitation effects (Black et al. (2008)). None of the effects we find have an impact at ages that would suggest an incapacitation effect. Both the ELR and EE have effects that are beyond the ages that would be binding. For example, the EE leads to greater propensity of delaying fertility after the age of 27 , which is after the typical age that a degree would be completed. While we can rule out the incapacitation effect, we cannot distinguish between a direct human capital or signaling effect of education on fertility timing. The small additional time in school as a result of the ELR suggests that any effects found would be driven more by signaling, and therefore an improvement in labour market opportunities. However, the effects of the EE reform could well be a combination of improvements in human capital and signaling of qualification effects. 


\section{References}

Anderberg, D. and Y. Zhu (2014). What a difference a term makes: the effect of educational attainment on marital outcomes on the UK. Journal of Population Economics 27, $387-419$.

Arrow, K. J. (1973). Higher education as a filter. Journal of Public Economics 2, 193-216.

Black, S. E., P. J. Devereux, and K. G. Salvanes (2008). Staying in the classroom and out of the maternity ward? The effect of compulsory schooling laws on teenage births. Economic Journal 118(530), 1025-1054.

Blanden, J., P. Gregg, and S. Machin (2003). Changes in educational inequality. Mimeo.

Blanden, J. and S. Machin (2004). Educational inequality and the expansion of uk higher education. Scottish Journal of Political Economy 51(2), 230-249.

Braakmann, N. (2011). The causal relationship between education, health and health related behaviour: Evidence from a natural experiment in England. Journal of Health Economics 30, 753-763.

Buckles, K. S. and D. M. Hungerman (2013). Season of Birth and Later Outcomes: Old Questions, New Answers. Review of Economics and Statistics 95, 711-724.

Carneiro, P., K. L. ken, and K. G. Salvanes (2013). A flying start? Maternity leave and long-term outcomes for mother and child. Mimeo.

Chevalier, A. and T. K. Viitanen (2003). The long-run labour market consequences of teenage motherhood in Britain. Journal of Population Economics 16(2), 323-343.

Danzer, N. and V. Lavy (2013). Parental leave and children's schooling outcomes: Quasiexperimental evidence from a large parental leave reform. NBER Working Papers 19452, National Bureau of Economic Research, Inc.

Del Bono, E. and F. Galindo-Rueda (2007). The long term impacts of compulsory schooling: Evidence from a natural experiment in school leaving dates. Discussion Paper CEE DP 74, Centre for the Economics of Education, London School of Economics, London.

Devereux, P. and W. Fan (2011). Earnings returns to the British education expansion. Economics of Education Review 30(6), 1153-1166. 
Dickson, M. and S. Smith (2011). What determines the return to education: An extra year or a hurdle cleared? Economics of Education Review 30(6), 1167-1176.

Etilé, F. and A. M. Jones (2011). Schooling and smoking among the baby boomers An evaluation of the impact of educational expansion in France. Journal of Health Economics 30(4), 811-831.

Fort, M., N. Schneeweis, and R. Winter-Ebmer (2014). More schooling, more children? Compulsory schooling and fertility in Europe. CESifo Working Paper 5068, Centre for Economic Studies \& Ifo Institute, Munich.

Francesconi, M. (2008). Adult outcomes for children of teenage mothers. Scandinavian Journal of Economics 110(1), 93-117.

Gelman, A. and G. Imbens (2014). Why high-order polynomials should not be used in regression discontinuity designs. NBER Working Papers 20405, National Bureau of Economic Research, Inc.

Geronimus, A. and S. Korenman (1992). The socioeconomic consequences of teen childbearing reconsidered. The Quarterly Journal of Economics 10\%, 1187-1214.

Gray, J., D. Jesson, and M. Tranmer (1993). Boosting post-16 participation in full time education: A study of some key factors in England and Wales. Youth Cohort Study 20, Employment Department, Sheffield.

Grogger, J. and S. Bronars (1993). The socioeconomic consequences of teenage childbearing: Result from a natural experiment. Family Planning Perspectives 25, 156-161.

Harmon, C. and I. Walker (1995). Estimates of the economic return to schooling for the United Kingdom. The American Economic Review 85(5), 1278-1286.

Hotz, J., S. W. McElroy, and S. G. Sanders (2005). Teenage childbearing and its life cycle consequences exploiting a natural experiment. Journal of Human Resources 40, $683-715$.

Ichino, A. and R. Winter-Ebmer (2004). The long-run educational cost of World War II. Journal of Labor Economics 22(1), 215-238.

James, J. (2015). Health and education expansion. Economics of Education Review 49, 193-215. 
Jolly, M., N. Sebire, J. Harris, S. Robinson, and L. Regan (2000). The risks associated with pregnancy in women aged 35 years or older. Human Reproduction 15, 2433-2437.

Kearney, M. S. and P. B. Levine (2012). Why is the teen birth rate in the United States so high and why does it matter? Journal of Economic Perspectives 26(2), 141-163.

Lleras-Muney, A. (2005). The relationship between education and adult mortality in the United States. Review of Economic Studies 72(1), 189-221.

Lochner, L. (2004). Education, work, and crime: A human capital approach. International Economic Review 45, 811-843.

Lochner, L. and E. Moretti (2004). The effect of education on crime: Evidence from prison inmates, arrests, and self-reports. The American Economic Review 94, 155-189.

Machin, S. J., O. Marie, and S. Vujić (2011). The crime reducing effect of education. The Economic Journal 121, 463-484.

Machin, S. J., O. Marie, and S. Vujić (2012). Youth crime and education expansion. German Economic Review (Special Issue on Economics of Crime) 13(4), 366-384.

Maurin, E. and S. McNally (2008). Vive la révolution! Long term returns of 1968 to the angry students. Journal of Labor Economics 26(1), 1-33.

Milligan, K., E. Moretti, and P. Oreopoulos (2004). Does education improve citizenship? Evidence from the United States and the United Kingdom. Journal of Public Economics 88(9-10), 1667-1695.

Nordin, M. (2014). Does eligibility for tertiary education affect crime rates? Quasiexperimental evidence. Working Paper 14, Lund University.

Oreopoulos, P. (2006). Estimating average and local average treatment effects of education when compulsory schooling laws really matter. The American Economic Review 96(1), $152-175$.

Osili, U. O. and B. T. Long (2008). Does Female Schooling Reduce Fertility? Evidence from Nigeria. Journal of Development Economics 87, 57-75.

Park, C. and C. Kang (2008). Does education induce healthy lifestyle? Journal of Health Economics 27(6), 1516-1531. 
Ribar, D. (1994). Teenage fertility and high school completion. Review of Economics and Statistics 76, 413-424.

Silles, M. A. (2011). The effect of schooling on teenage childbearing: evidence using changes in compulsory education laws. Journal of Population Economics 24, 761-777.

Spence, M. (1973). Job market signaling. The Quarterly Journal of Economics 87(3), $355-374$.

Thomas, D., J. Strauss, and M.-H. Henriques (1991). How does mother's education affect child height? Journal of Human Resources 26(2), 183-211.

Walker, I. and Y. Zhu (2008). The causal effect of teen motherhood on worklessness. Working Paper KDPE 0917, University of Kent.

Wilson, T. J. (2012). Compulsory education and teenage motherhood. Mimeo.

Wooldridge, J. M. (2009). Introductory Econometrics: A Modern Approach (4th ed.). South-Western: Thomson. 


\section{Figures and Tables}

Figure 1: Changes in post-compulsory education participation from 1985 to 2000

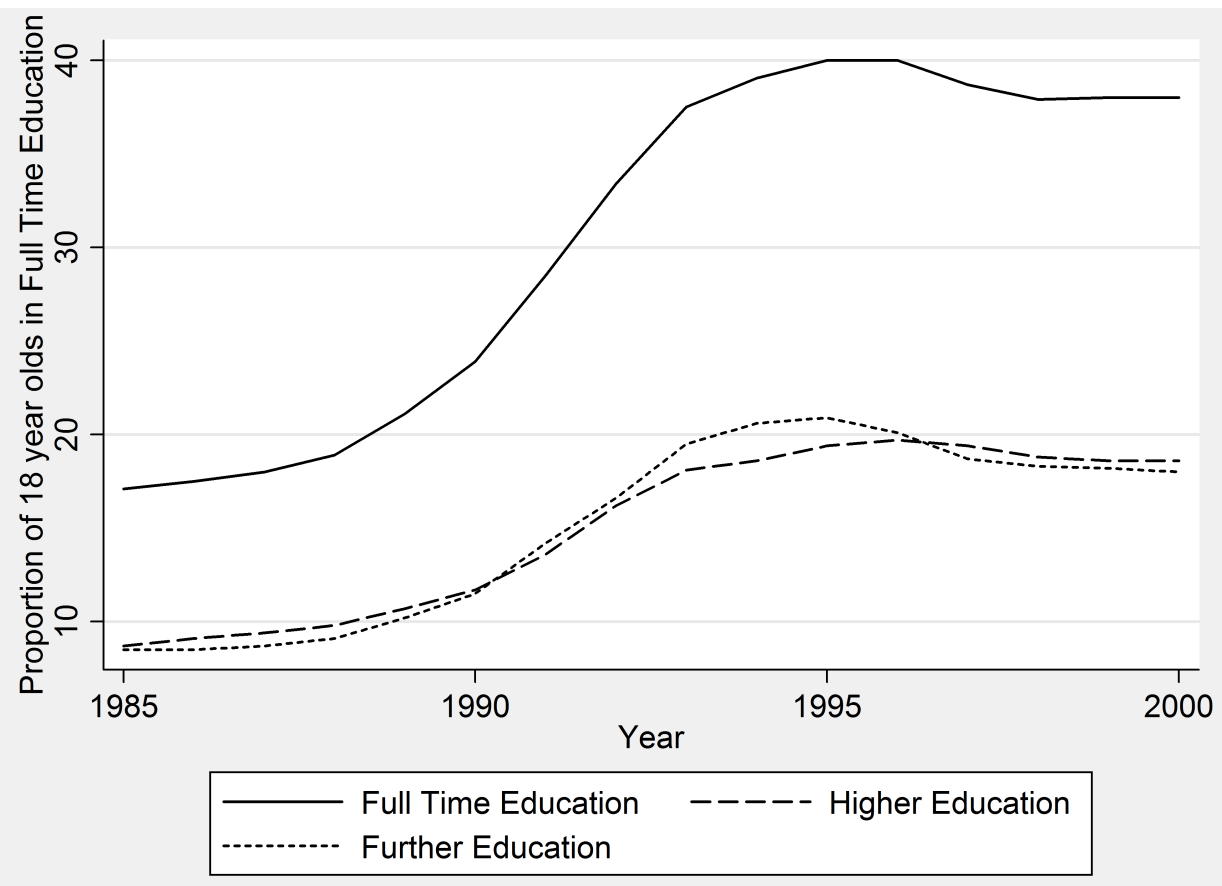


Figure 2: ELR: Qualifications

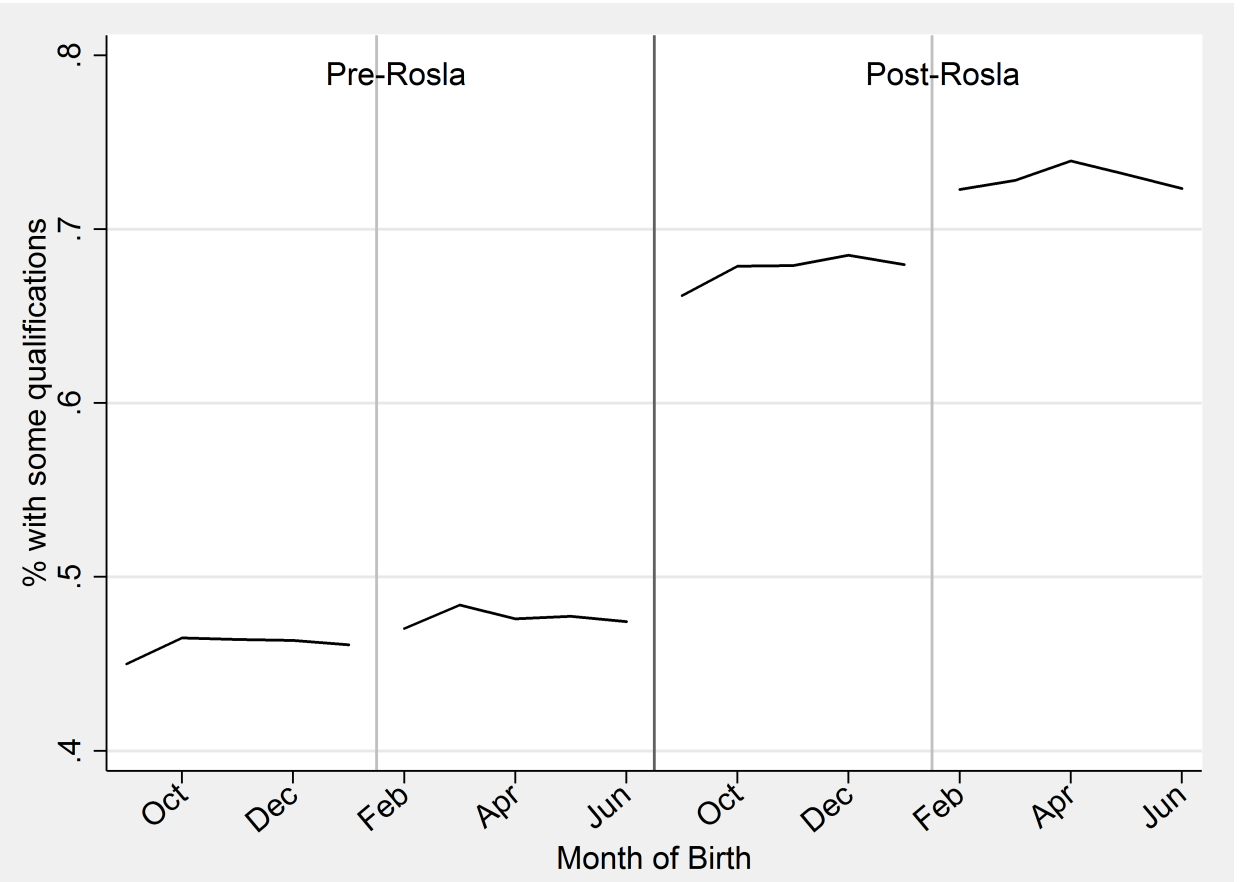

Note: Each square represents the mean qualifications held by month of birth separated into two time periods: i) pre-RoSLA, before the raising of the school leaving age, this includes those born from 1940 up to August 1957 and ii) post-RoSLA, including those born on or after September 1957 up to December 1969. The lines are non-parametrically fitted using a triangle kernel with a bandwidth of three. 
Figure 3: ELR: Teen Births and Births After Aged 24
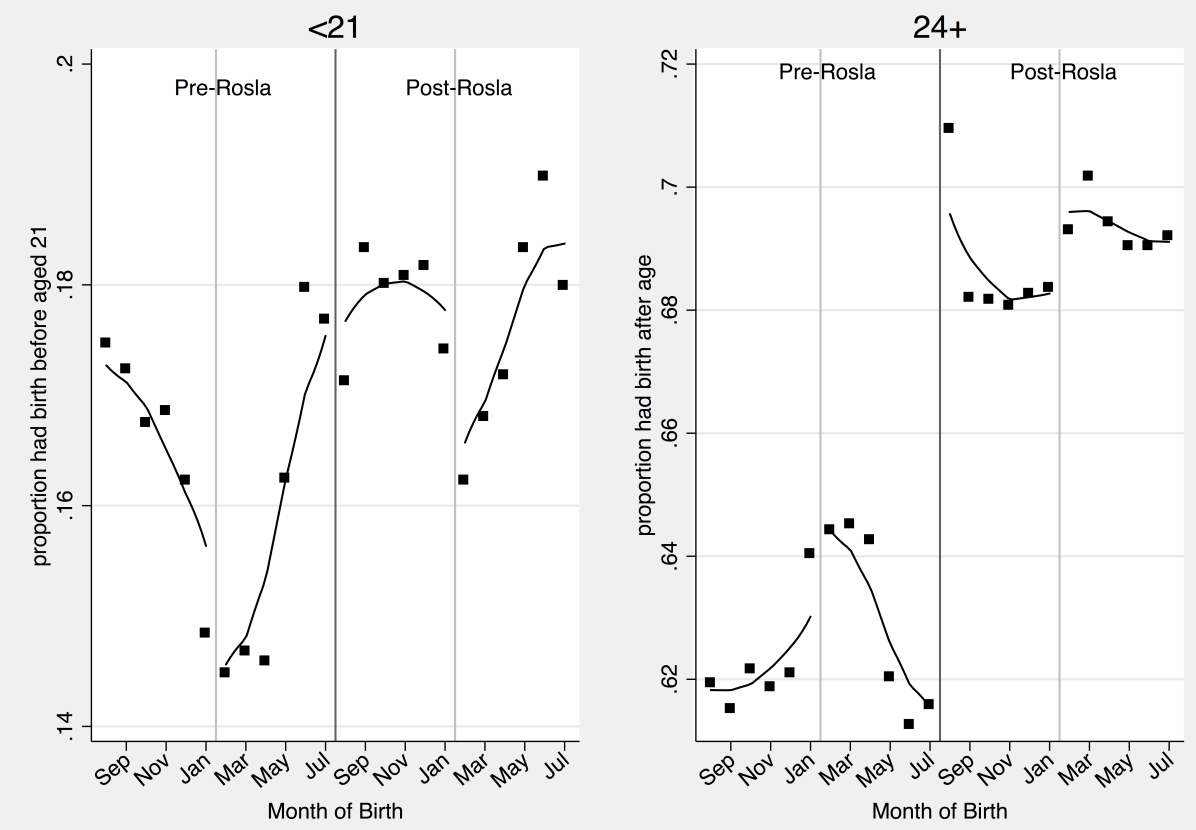

Note: Each square represents the mean of the outcome by month of birth separated into two time periods: i) pre-RoSLA, before the raising of the school leaving age, this includes those born from 1940 up to August 1957 and ii) post-RoSLA, including those born on or after September 1957 up to December 1969. The lines are non-parametrically fitted using a triangle kernel with a bandwidth of three.

Figure 4: ELR: Birth after age 26 and 30
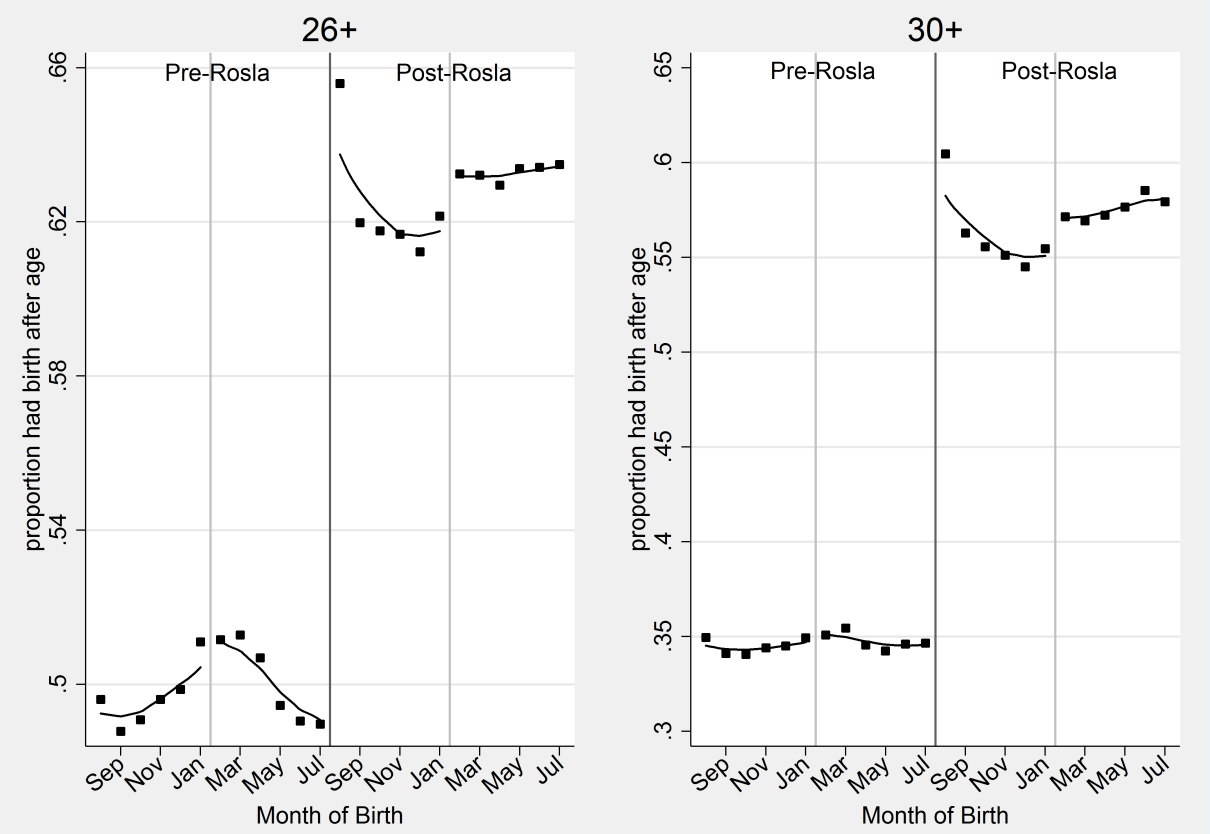

Note: Each square represents the mean of the outcome by month of birth separated into two time periods: i) pre-RoSLA, before the raising of the school leaving age, this includes those born from 1940 up to August 1957 and ii) post-RoSLA, including those born on or after September 1957 up to December 1969. The lines are non-parametrically fitted using a triangle kernel with a bandwidth of three. 
Figure 5: Education (Age left full-time schooling and Degree) controlling for a cubic in age
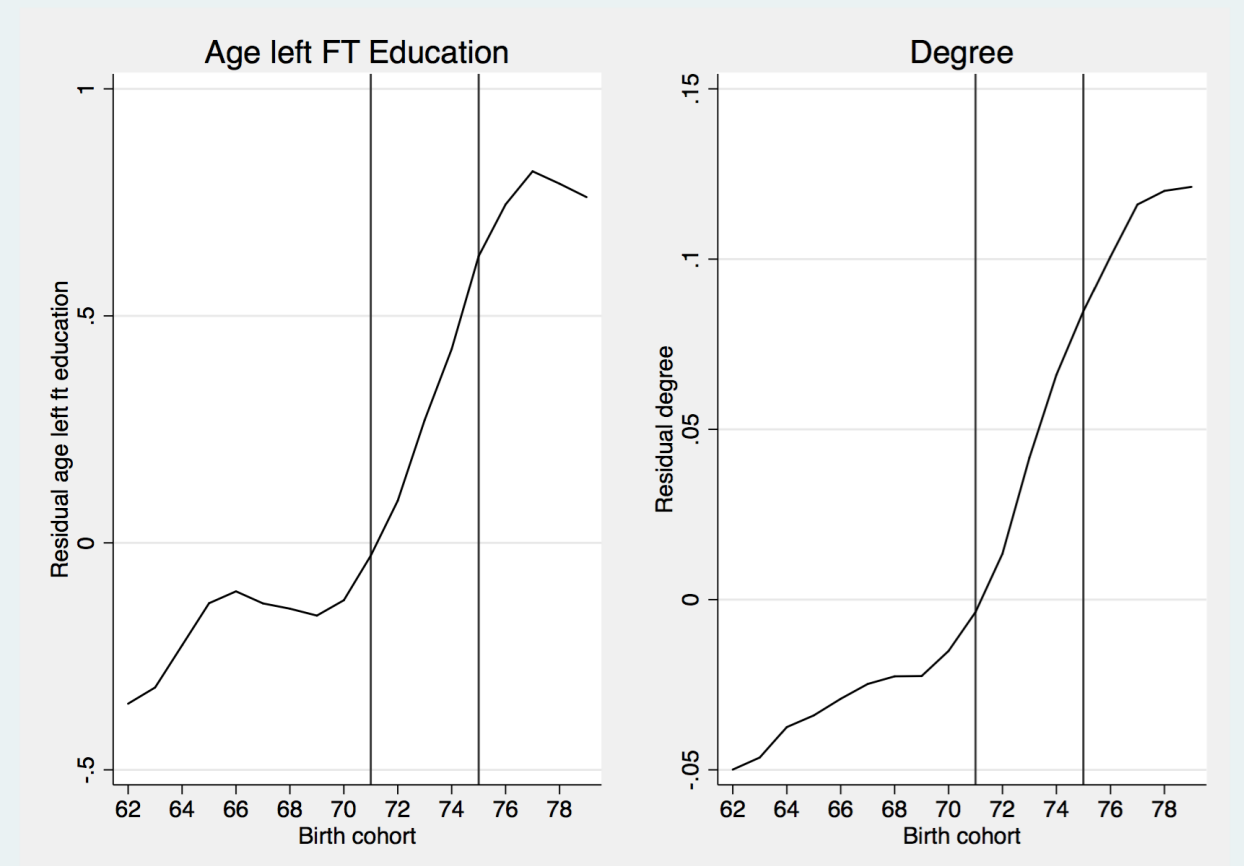

Figure 6: Education (Post-16 schooling and No qualifications) controlling for a cubic in age
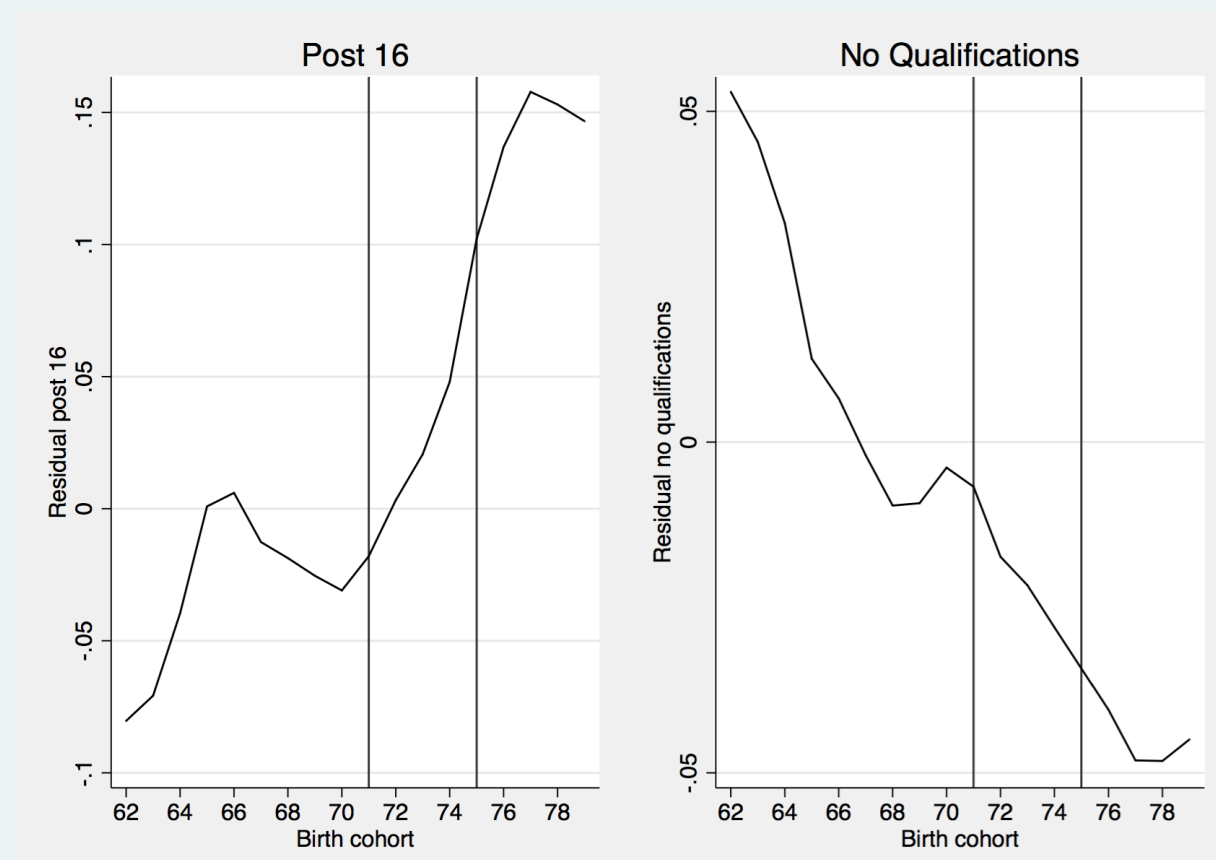
Figure 7: Probability of teen birth controlling for a cubic age profile

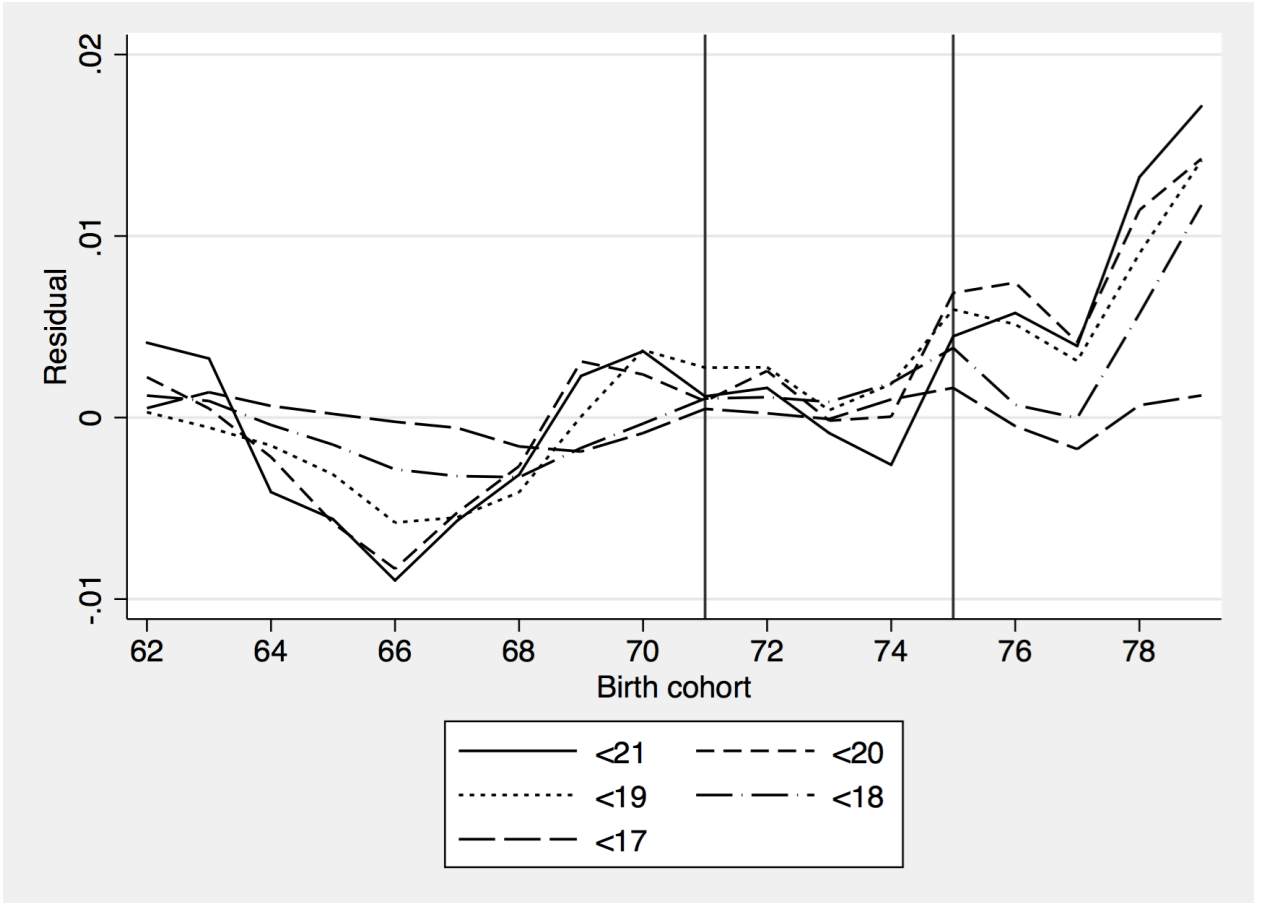

Figure 8: Probability of birth after age 20 controlling for a cubic age profile

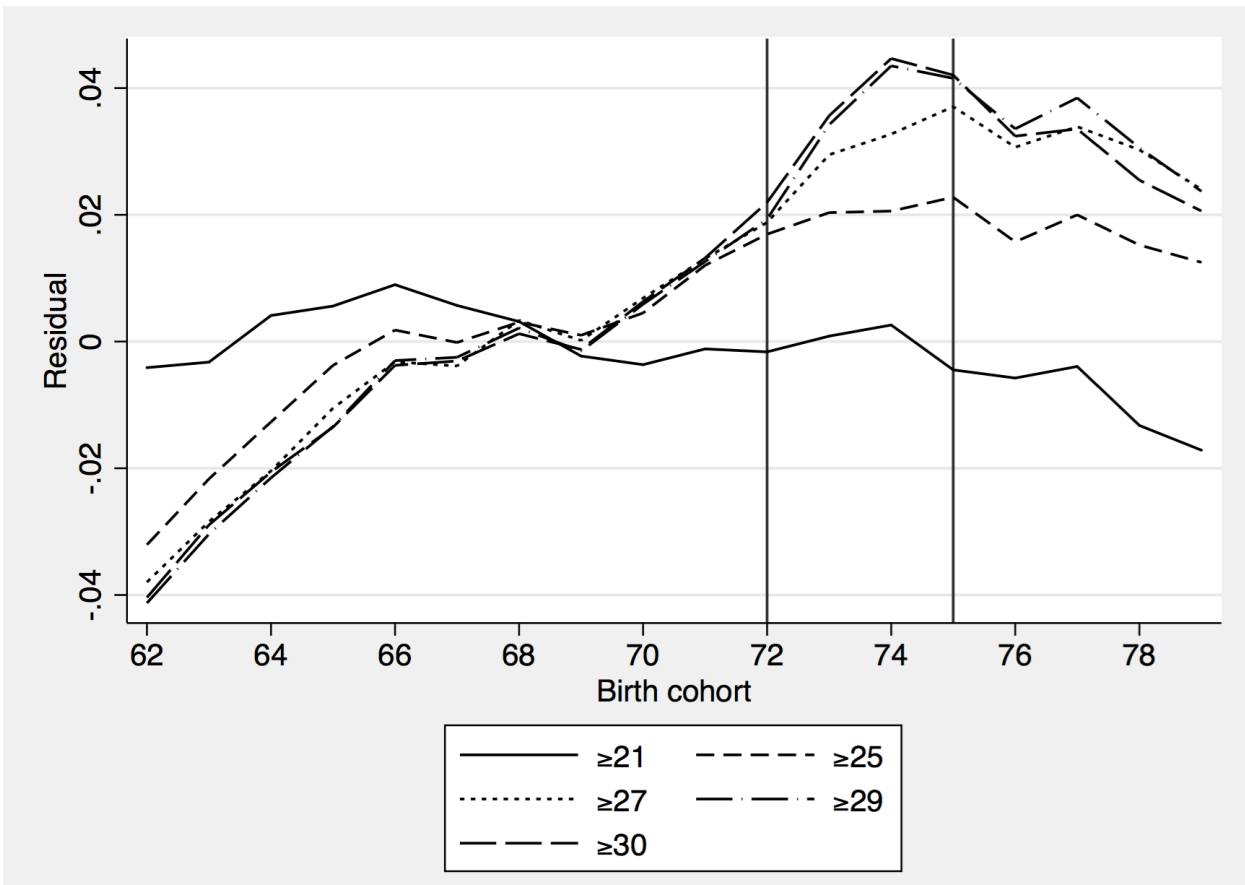


Table 1: Easter Leaving Rule (ELR) and Educational Attainment

\begin{tabular}{rcccccccc}
\hline & $(1)$ & $(2)$ & $(3)$ & $(4)$ & $(5)$ & $(6)$ & $(7)$ & $(8)$ \\
\hline & & & & & & & & \\
ELR & $0.0448^{* * *}$ & 0.00657 & & & & & & \\
& $(0.00742)$ & $(0.00650)$ & & & & & & \\
RoSLA*ELR & & & $0.0300^{* * *}$ & $0.0360^{* * *}$ & $0.0368^{* * *}$ & $0.0386^{* * *}$ & $0.0366^{* * *}$ & $0.0301^{* * *}$ \\
& & & $(0.00462)$ & $(0.00510)$ & $(0.00510)$ & $(0.00568)$ & $(0.00659)$ & $(0.00804)$ \\
Constant & $51.13^{* * *}$ & $28.71^{* * *}$ & $40.23^{* * *}$ & $37.41^{* * *}$ & $66.00^{* * *}$ & $70.60^{* * *}$ & $86.71^{* * *}$ & $120.4^{* * *}$ \\
& $(8.212)$ & $(7.141)$ & $(5.400)$ & $(5.840)$ & $(6.715)$ & $(7.488)$ & $(9.047)$ & $(12.42)$ \\
Window & All & All & All & Sep-Jun & Sep-Jun & Oct-May & Nov-Apr & Dec-Mar \\
RoSLA period & Post & Pre & Both & Both & Both & Both & Both & Both \\
Observations & 66,574 & 105,568 & 172,142 & 142,268 & 142,268 & 113,999 & 84,586 & 56,939 \\
$R^{2}$ & 0.015 & 0.014 & 0.068 & 0.066 & 0.067 & 0.067 & 0.068 & 0.068 \\
$F$-test & 36.40 & 1.021 & 42.17 & 50.01 & 52.13 & 46.08 & 30.75 & 14.03 \\
$p$-value & 0.00 & 0.31 & 0.00 & 0.00 & 0.00 & 0.00 & 0.00 & 0.00 \\
\hline
\end{tabular}

Notes: Robust standard errors in parenthesis, ${ }^{*},{ }^{* *}$ and ${ }^{* * *}$ respectively denote significance at the 10,5 or 1 percent level. The dependent variable is educational qualifications attainment. The $E L R$ is a dummy variable equal to one if an individual was born between February and August, and zero otherwise. Columns (1) and (2) regress holding any qualifications on the ELR post- (column (1)) and pre-RoSLA (column (2)). Columns (3) to (8) estimate the RD-DD specification without (coumns (3) and (4)) and with a quadratic spline (columns (5) to (8)). All specifications include age, age squared, non-white, living in London, birth cohort dummies, year of survey dummies. The $F$-stat is a test for the joint significance of the excluded instruments $E L R \times R o S L A$, the $p$-value corresponds to this $F$-test. 
Table 2: Education Expansion (EE) and Education Attainment

\begin{tabular}{lrrrr}
\hline & $(1)$ & $(2)$ & $(3)$ & $(4)$ \\
& Age left FT Ed & Post 16 & Degree & No Qual \\
\hline & & & & \\
Cohort 1972 & $0.181^{* * *}$ & $0.026^{* * *}$ & $0.017^{* * *}$ & -0.001 \\
Cohort 1973 & $(0.034)$ & $(0.008)$ & $(0.005)$ & $(0.005)$ \\
& $0.394^{* * *}$ & $0.048^{* * *}$ & $0.045^{* * *}$ & -0.003 \\
Cohort 1974 & $(0.041)$ & $(0.009)$ & $(0.006)$ & $(0.006)$ \\
& $0.538^{* * *}$ & $0.084^{* * *}$ & $0.064^{* * *}$ & $-0.011^{*}$ \\
Cohort 1975 & $(0.048)$ & $(0.010)$ & $(0.008)$ & $(0.007)$ \\
& $0.788^{* * *}$ & $0.161^{* * *}$ & $0.075^{* * *}$ & $-0.018^{* *}$ \\
Post EE & $(0.058)$ & $(0.012)$ & $(0.010)$ & $(0.008)$ \\
& $0.952^{* * *}$ & $0.242^{* * *}$ & $0.088^{* * *}$ & $-0.041^{* * *}$ \\
Constant & $(0.075)$ & $(0.016)$ & $(0.013)$ & $(0.010)$ \\
& $-7.482^{* * *}$ & $-10.842^{* * *}$ & -0.009 & $5.667^{* * *}$ \\
Observations & $(2.584)$ & $(0.572)$ & $(0.452)$ & $(0.417)$ \\
$R^{2}$ & 133,082 & 133,082 & 123,800 & 123,932 \\
$F$-test & 0.108 & 0.068 & 0.085 & 0.013 \\
$p$-value & 44.4 & 58.8 & 18.5 & 4.92 \\
\hline
\end{tabular}

Notes: Robust standard errors in parenthesis, ${ }^{*},{ }^{* *}$ and ${ }^{* * *}$ respectively denote significance at the 10,5 or 1 percent level. All specifications include a cubic polynomial in age, quadratic in year of birth, and year of survey dummies. The sample is aged between 23 and 34 and includes cohorts born between 1962 and 1980. The $F$-stat is a test for the joint significance of the 1972 to 1975 , and post expansion cohort dummies, the $p$-value corresponds to this $F$-test. The dependent variable in column (1) is is a variable defining the age the individual left full-time education, column (2) is a dummy equal to 1 if the individual left school after age 16, column (3) is a dummy if the highest qualification achieved is an A-level (or equivalent) or above, and column (4) is a dummy equal to 1 representing whether the individual has no qualifications. 
Table 3: Effect of the Easter Leaving Rule and Education Expansion on Age at First Birth: Teen Births

\begin{tabular}{|c|c|c|c|c|c|c|c|}
\hline & $\begin{array}{r}(1) \\
\text { Age at } \\
\text { First Birth }\end{array}$ & $<16$ & $<17$ & $<18$ & $<19$ & $<20$ & $\begin{array}{r}(7) \\
<21\end{array}$ \\
\hline \multicolumn{8}{|l|}{ Panel A: ELR } \\
\hline RD-DD & $\begin{array}{l}-0.0444 \\
(0.0536)\end{array}$ & $\begin{array}{l}-0.000215 \\
(0.000636)\end{array}$ & $\begin{array}{c}0.00151 \\
(0.00108)\end{array}$ & $\begin{array}{c}0.00276 \\
(0.00187)\end{array}$ & $\begin{array}{c}-0.000961 \\
(0.00271)\end{array}$ & $\begin{array}{l}-0.00326 \\
(0.00348)\end{array}$ & $\begin{array}{l}-0.00264 \\
(0.00409)\end{array}$ \\
\hline RD-DD quadratic spline & $\begin{array}{c}-0.0299 \\
(0.0536)\end{array}$ & $\begin{array}{l}-0.000226 \\
(0.000635)\end{array}$ & $\begin{array}{c}0.00142 \\
(0.00108)\end{array}$ & $\begin{array}{c}0.00255 \\
(0.00186)\end{array}$ & $\begin{array}{l}-0.00131 \\
(0.00271)\end{array}$ & $\begin{array}{l}-0.00371 \\
(0.00347)\end{array}$ & $\begin{array}{l}-0.00316 \\
(0.00409)\end{array}$ \\
\hline Observations & 90,815 & 137,979 & 137,979 & 137,979 & 137,979 & 137,979 & 137,979 \\
\hline \multicolumn{8}{|l|}{ Panel B: EE } \\
\hline Cohort 1972 & $\begin{array}{l}0.175^{*} \\
(0.099)\end{array}$ & $\begin{array}{c}0.001 \\
(0.001)\end{array}$ & $\begin{array}{l}-0.000 \\
(0.002)\end{array}$ & $\begin{array}{l}-0.001 \\
(0.003)\end{array}$ & $\begin{array}{l}-0.001 \\
(0.004)\end{array}$ & $\begin{array}{c}0.000 \\
(0.005)\end{array}$ & $\begin{array}{l}-0.003 \\
(0.005)\end{array}$ \\
\hline Cohort 1973 & $\begin{array}{c}0.304^{* * *} \\
(0.112)\end{array}$ & $\begin{array}{l}-0.000 \\
(0.001)\end{array}$ & $\begin{array}{l}-0.001 \\
(0.002)\end{array}$ & $\begin{array}{l}-0.004 \\
(0.003)\end{array}$ & $\begin{array}{l}-0.007 \\
(0.004)\end{array}$ & $\begin{array}{l}-0.006 \\
(0.005)\end{array}$ & $\begin{array}{l}-0.009 \\
(0.006)\end{array}$ \\
\hline Cohort 1974 & $\begin{array}{c}0.279^{* *} \\
(0.131)\end{array}$ & $\begin{array}{c}0.001 \\
(0.001)\end{array}$ & $\begin{array}{l}-0.000 \\
(0.002)\end{array}$ & $\begin{array}{c}-0.007^{*} \\
(0.004)\end{array}$ & $\begin{array}{c}-0.009^{*} \\
(0.005)\end{array}$ & $\begin{array}{c}-0.011^{*} \\
(0.006)\end{array}$ & $\begin{array}{c}-0.018^{* *} \\
(0.007)\end{array}$ \\
\hline Cohort 1974 & $\begin{array}{l}0.279^{*} \\
(0.151)\end{array}$ & $\begin{array}{c}0.000 \\
(0.001)\end{array}$ & $\begin{array}{c}0.001 \\
(0.003)\end{array}$ & $\begin{array}{l}-0.006 \\
(0.004)\end{array}$ & $\begin{array}{l}-0.007 \\
(0.006)\end{array}$ & $\begin{array}{l}-0.005 \\
(0.008)\end{array}$ & $\begin{array}{l}-0.013 \\
(0.009)\end{array}$ \\
\hline Post EE & $\begin{array}{c}0.549^{* * *} \\
(0.197)\end{array}$ & $\begin{array}{l}-0.001 \\
(0.002)\end{array}$ & $\begin{array}{l}-0.005 \\
(0.003)\end{array}$ & $\begin{array}{c}-0.018^{* * *} \\
(0.006)\end{array}$ & $\begin{array}{c}-0.020^{* *} \\
(0.008)\end{array}$ & $\begin{array}{c}-0.018^{*} \\
(0.010)\end{array}$ & $\begin{array}{c}-0.027^{* *} \\
(0.011)\end{array}$ \\
\hline Constant & $\begin{array}{c}3.586 \\
(7.193)\end{array}$ & $\begin{array}{c}0.069 \\
(0.061)\end{array}$ & $\begin{array}{l}0.219^{*} \\
(0.117)\end{array}$ & $\begin{array}{c}0.726^{* * *} \\
(0.205)\end{array}$ & $\begin{array}{c}0.220 \\
(0.289)\end{array}$ & $\begin{array}{l}-0.557 \\
(0.358)\end{array}$ & $\begin{array}{c}-0.886^{* *} \\
(0.413)\end{array}$ \\
\hline Observations & 49,974 & 133,082 & 133,082 & 133,082 & 133,082 & 133,082 & 133,082 \\
\hline$R^{2}$ & 0.285 & 0.000 & 0.000 & 0.001 & 0.002 & 0.006 & 0.013 \\
\hline$F$-test & 1.98 & 0.79 & 1.66 & 3.17 & 1.75 & 1.24 & 1.65 \\
\hline$p$-value & 0.079 & 0.56 & 0.14 & 0.0073 & 0.12 & 0.29 & 0.14 \\
\hline
\end{tabular}

specifications include age, age squared, non-white, living in London, birth cohort dummies, year of survey dummies, also with and without a quadratic spline. The sample of women is aged between 23 and 34, born between October and May of 1940-1969, who left school at 16 or earlier In panel $\mathrm{B}$ all specifications include a cubic polynomial in lnetwee 23 and 34 and in jointly equal to zero. 
Table 4: Effect of the Easter Leaving Rule and Education Expansion on Age at First Birth: Delaying Fertility

\begin{tabular}{|c|c|c|c|c|c|c|c|c|c|c|}
\hline & $\begin{array}{r}(1) \\
\geq 21\end{array}$ & $\begin{array}{r}(2) \\
\geq 22\end{array}$ & $\begin{array}{r}(3) \\
\geq 23\end{array}$ & $\begin{array}{r}(4) \\
\geq 24\end{array}$ & $\begin{array}{r}(5) \\
\geq 25\end{array}$ & $\begin{array}{r}(6) \\
\geq 26\end{array}$ & $\begin{array}{r}(7) \\
\geq 27\end{array}$ & $\begin{array}{r}(8) \\
\geq 28\end{array}$ & $\begin{array}{r}(9) \\
\geq 29\end{array}$ & $\begin{array}{r}(10) \\
\geq 30\end{array}$ \\
\hline \multicolumn{11}{|l|}{ Panel A: ELR } \\
\hline RD-DD & $\begin{array}{c}0.00264 \\
(0.00409)\end{array}$ & $\begin{array}{l}0.000691 \\
(0.00455)\end{array}$ & $\begin{array}{l}0.000601 \\
(0.00488)\end{array}$ & $\begin{array}{c}0.00664 \\
(0.00508)\end{array}$ & $\begin{array}{c}0.00777 \\
(0.00518)\end{array}$ & $\begin{array}{c}0.0114^{* *} \\
(0.00519)\end{array}$ & $\begin{array}{c}0.0148^{* * *} \\
(0.00515)\end{array}$ & $\begin{array}{c}0.0146^{* * *} \\
(0.00508)\end{array}$ & $\begin{array}{c}0.0171^{* * *} \\
(0.00500)\end{array}$ & $\begin{array}{c}0.0181^{* * *} \\
(0.00493)\end{array}$ \\
\hline RD-DD quadratic spline & $\begin{array}{c}0.00316 \\
(0.00409)\end{array}$ & $\begin{array}{c}0.00129 \\
(0.00455)\end{array}$ & $\begin{array}{c}0.00123 \\
(0.00488)\end{array}$ & $\begin{array}{c}0.00730 \\
(0.00508)\end{array}$ & $\begin{array}{c}0.00845 \\
(0.00518)\end{array}$ & $\begin{array}{c}0.0121^{* *} \\
(0.00519)\end{array}$ & $\begin{array}{c}0.0155^{* * *} \\
(0.00515)\end{array}$ & $\begin{array}{c}0.0153^{* * *} \\
(0.00508)\end{array}$ & $\begin{array}{c}0.0177^{* * *} \\
(0.00500)\end{array}$ & $\begin{array}{c}0.0187^{* * *} \\
(0.00493)\end{array}$ \\
\hline Observations & 137,979 & 137,979 & 137,979 & 137,979 & 137,979 & 137,979 & 137,979 & 137,979 & 137,979 & 137,979 \\
\hline Cohort 1972 & $\begin{array}{c}0.003 \\
(0.005)\end{array}$ & $\begin{array}{c}0.005 \\
(0.006)\end{array}$ & $\begin{array}{c}0.006 \\
(0.006)\end{array}$ & $\begin{array}{c}0.004 \\
(0.006)\end{array}$ & $\begin{array}{c}0.009 \\
(0.007)\end{array}$ & $\begin{array}{c}0.006 \\
(0.007)\end{array}$ & $\begin{array}{c}0.008 \\
(0.007)\end{array}$ & $\begin{array}{c}0.008 \\
(0.007)\end{array}$ & $\begin{array}{c}0.009 \\
(0.007)\end{array}$ & $\begin{array}{c}0.014^{*} \\
(0.007)\end{array}$ \\
\hline Cohort 1973 & $\begin{array}{c}0.009 \\
(0.006)\end{array}$ & $\begin{array}{c}0.007 \\
(0.007)\end{array}$ & $\begin{array}{c}0.009 \\
(0.007)\end{array}$ & $\begin{array}{l}0.013^{*} \\
(0.007)\end{array}$ & $\begin{array}{l}0.013^{*} \\
(0.008)\end{array}$ & $\begin{array}{l}0.014^{*} \\
(0.008)\end{array}$ & $\begin{array}{c}0.022^{* * *} \\
(0.008)\end{array}$ & $\begin{array}{c}0.025^{* * *} \\
(0.008)\end{array}$ & $\begin{array}{c}0.028^{* * *} \\
(0.008)\end{array}$ & $\begin{array}{c}0.030^{* * *} \\
(0.008)\end{array}$ \\
\hline Cohort 1974 & $\begin{array}{c}0.018^{* *} \\
(0.007)\end{array}$ & $\begin{array}{l}0.015^{*} \\
(0.008)\end{array}$ & $\begin{array}{c}0.016^{* *} \\
(0.008)\end{array}$ & $\begin{array}{c}0.013 \\
(0.009)\end{array}$ & $\begin{array}{c}0.013 \\
(0.009)\end{array}$ & $\begin{array}{l}0.017^{*} \\
(0.009)\end{array}$ & $\begin{array}{l}0.022^{* *} \\
(0.009)\end{array}$ & $\begin{array}{c}0.031^{* * *} \\
(0.009)\end{array}$ & $\begin{array}{c}0.039^{* * *} \\
(0.010)\end{array}$ & $\begin{array}{c}0.041^{* * *} \\
(0.010)\end{array}$ \\
\hline Observations & 133,082 & 133,082 & 133,082 & 133,082 & 133,082 & 133,082 & 133,082 & 133,082 & 133,082 & 133,082 \\
\hline$R^{2}$ & 0.013 & 0.021 & 0.032 & 0.046 & 0.063 & 0.082 & 0.102 & 0.125 & 0.148 & 0.170 \\
\hline$F$-test & 1.65 & 0.79 & 0.92 & 0.77 & 1.05 & 1.26 & 2.59 & 4.27 & 5.31 & 6.36 \\
\hline$p$-value & 0.14 & 0.56 & 0.47 & 0.57 & 0.39 & 0.28 & 0.02 & 0.00 & 0.00 & 0.00 \\
\hline
\end{tabular}

Notes: Robust standard errors in parenthesis, ${ }^{*},{ }^{* *}$ and ${ }^{* * *}$ respectively denote significance at the 10,5 or 1 percent level. In panel A all specifications include age, age squared, non-white,
living in London, birth cohort dummies, year of survey dummies, also with and without a quadratic spline. The sample of women is aged between 23 and 34 , born between October and May of 1940-1969, who left school at 16 or earlier. In panel B all specifications include a cubic polynomial in age, quadratic in year of birth. The sample is aged between 23 and 34 and includes cohorts born between 1962 and 1979. The $F$-test tests whether the coefficients on the excluded instruments are jointly equal to zero. 
Table 5: OLS and IV Estimates of Education on Fertility Timing: Evidence from the Easter Leaving Rule and Education Expansion

\begin{tabular}{|c|c|c|c|c|c|c|c|c|c|c|}
\hline & \multicolumn{2}{|c|}{ Age of 1st Birth } & \multicolumn{2}{|c|}{ Teen Birth } & \multicolumn{2}{|c|}{ Aged 24 or above } & \multicolumn{2}{|c|}{ Aged 27 or above } & \multicolumn{2}{|c|}{ Aged 30 or above } \\
\hline Panel A: ELR & & & & & & & & & & \\
\hline Qual & $\begin{array}{c}1.216^{* * *} \\
(0.029)\end{array}$ & $\begin{array}{l}-1.066 \\
(1.171)\end{array}$ & $\begin{array}{c}-0.071 * * * \\
(0.002)\end{array}$ & $\begin{array}{l}-0.012 \\
(0.095)\end{array}$ & $\begin{array}{c}0.137^{* * *} \\
(0.003)\end{array}$ & $\begin{array}{c}0.116 \\
(0.141)\end{array}$ & $\begin{array}{c}0.112^{* * *} \\
(0.003)\end{array}$ & $\begin{array}{c}0.309^{* *} \\
(0.147)\end{array}$ & $\begin{array}{c}0.081^{* * * *} \\
(0.003)\end{array}$ & $\begin{array}{c}0.405^{* * *} \\
(0.146)\end{array}$ \\
\hline Observations & 75,500 & 75,500 & 113,999 & 113,999 & 113,999 & 113,999 & 113,999 & 113,999 & 113,999 & 113,999 \\
\hline Hausman Test ( $p$-value) & & 0.041 & & 0.54 & & 0.88 & & 0.18 & & 0.020 \\
\hline \multicolumn{11}{|l|}{ Panel B: EE } \\
\hline Age Left FTE & $\begin{array}{c}0.746^{* * *} \\
(0.010)\end{array}$ & $\begin{array}{c}0.553^{* * *} \\
(0.209)\end{array}$ & $\begin{array}{c}-0.029 * * * \\
(0.000)\end{array}$ & $\begin{array}{l}-0.013 \\
(0.009)\end{array}$ & $\begin{array}{c}0.063^{* * *} \\
(0.000)\end{array}$ & $\begin{array}{c}0.020 \\
(0.012)\end{array}$ & $\begin{array}{c}0.072^{* * *} \\
(0.001)\end{array}$ & $\begin{array}{c}0.039^{* * *} * \\
(0.013)\end{array}$ & $\begin{array}{c}0.070 * * * \\
(0.001)\end{array}$ & $\begin{array}{c}0.052^{* * *} \\
(0.013)\end{array}$ \\
\hline Observations & 49,974 & 49,974 & 133,082 & 133,082 & 133,639 & 133,639 & 133,082 & 133,082 & 133,082 & 133,082 \\
\hline Hansen $\mathbf{J}$ ( $p$-value) & & 0.36 & & 0.39 & & 0.91 & & 0.35 & & 0.00 \\
\hline Hausman Test ( $p$-value) & & 0.38 & & 0.06 & & 0.00027 & & 0.01 & & 0.19 \\
\hline \multicolumn{11}{|l|}{ Panel $C: E E$} \\
\hline Degree & $\begin{array}{c}3.964^{* * *} \\
(0.061)\end{array}$ & $\begin{array}{c}5.907 * * \\
(2.307)\end{array}$ & $\begin{array}{c}-0.113^{* * *} \\
(0.002)\end{array}$ & $\begin{array}{l}-0.127 \\
(0.083)\end{array}$ & $\begin{array}{c}0.293^{* * *} \\
(0.002)\end{array}$ & $\begin{array}{c}0.193^{*} \\
(0.113)\end{array}$ & $\begin{array}{c}0.371^{* * *} \\
(0.003)\end{array}$ & $\begin{array}{c}0.380^{* * *} \\
(0.118)\end{array}$ & $\begin{array}{c}0.369 * * * \\
(0.004)\end{array}$ & $\begin{array}{c}0.574^{* * *} \\
(0.122)\end{array}$ \\
\hline Observations & 48,858 & 48,858 & 123,800 & 123,800 & 123,800 & 123,800 & 123,800 & 123,800 & 123,800 & 123,800 \\
\hline Hansen $\mathrm{J}$ ( $p$-value) & & 0.39 & & 0.47 & & 0.99 & & 0.83 & & 0.16 \\
\hline Hausman Test ( $p$-value) & & 0.37 & & 0.84 & & 0.38 & & 0.94 & & 0.083 \\
\hline \multicolumn{11}{|l|}{ Panel D: EE } \\
\hline Post 16 & $\begin{array}{c}2.406^{* * *} \\
(0.034)\end{array}$ & $\begin{array}{c}1.618^{* *} \\
(0.794)\end{array}$ & $\begin{array}{c}-0.121^{* * *} \\
(0.002)\end{array}$ & $\begin{array}{l}-0.056 \\
(0.036)\end{array}$ & $\begin{array}{c}0.231^{* * *} \\
(0.002)\end{array}$ & $\begin{array}{c}0.052 \\
(0.050)\end{array}$ & $\begin{array}{c}0.246^{* * *} \\
(0.002)\end{array}$ & $\begin{array}{c}0.075 \\
(0.053)\end{array}$ & $\begin{array}{c}0.229 * * * \\
(0.002)\end{array}$ & $\begin{array}{c}0.053 \\
(0.054)\end{array}$ \\
\hline Observations & 49,974 & 49,974 & 133,082 & 133,082 & 133,082 & 133,082 & 133,082 & 133,082 & 133,082 & 133,082 \\
\hline Hansen $\mathrm{J}$ ( $p$-value) & & 0.17 & & 0.41 & & 0.56 & & 0.020 & & $2.1 \mathrm{e}-06$ \\
\hline Hausman Test ( $p$-value) & & 0.35 & & 0.065 & & 0.00019 & & 0.00088 & & 0.00084 \\
\hline
\end{tabular}

Notes: Robust standard errors in parenthesis, ${ }^{*},{ }^{* *}$ and ${ }^{* * *}$ respectively denote significance at the 10,5 or 1 percent level. In panel A all specifications include age, age squared, non-white, living in London, birth cohort dummies, year of survey dummies, also with and without a quadratic spline. The sample of women is aged between 23 and 34, born between October and May of 1940-1969, who left school at 16 or earlier. In panels B, C and D all specifications include a cubic polynomial in age, quadratic in year of birth. The sample is aged between 23 and 34 and includes cohorts born between 1962 and 1979 . The pre-EE mean is the average taken for the cohorts before the first education expansion cohort of 1972. 


\section{Appendix: Additional Figures and Tables}

Figure A1: Robustness Checks: Birth After the Age of 27 (ELR)

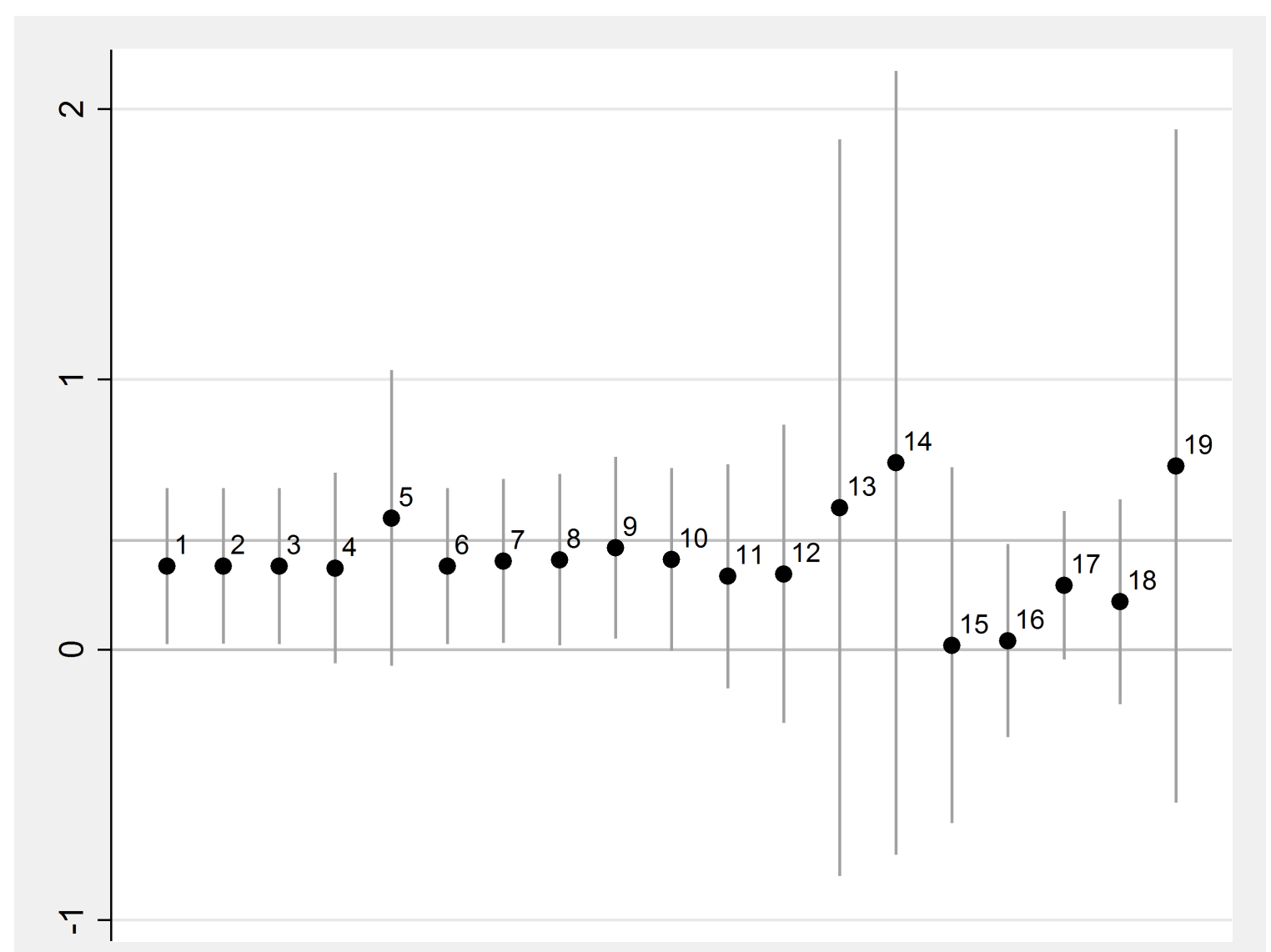

Notes: Each dot represents a point estimate from a separate 2SLS estimation. The upper horizontal line represents the baseline estimate and the lower is at zero. The vertical lines are the $95 \%$ confidence interval. The dots are from the following specifications: 1. Baseline with quadratic spline. 2. Cubic in the centered month of birth variable. 3. As in 2 but also includes cubic spline. 4. Restricts the month of birth window to November to April 5. Restricts the month of birth window to December to March. 6. The sample restricted to the cohorts 1940-1969. 7. The sample restricted to the cohorts 1941-1969. 8. The sample restricted to the cohorts 1942-1969. 9. The sample restricted to the cohorts 1943-1969. 10. The sample restricted to the cohorts 1944-1969. 11.-18. Uses fake month of birth $\times$ RoSLA interaction as the instrument, running from March to November. 
Figure A2: Robustness Checks: Birth After the Age of 30 (ELR)

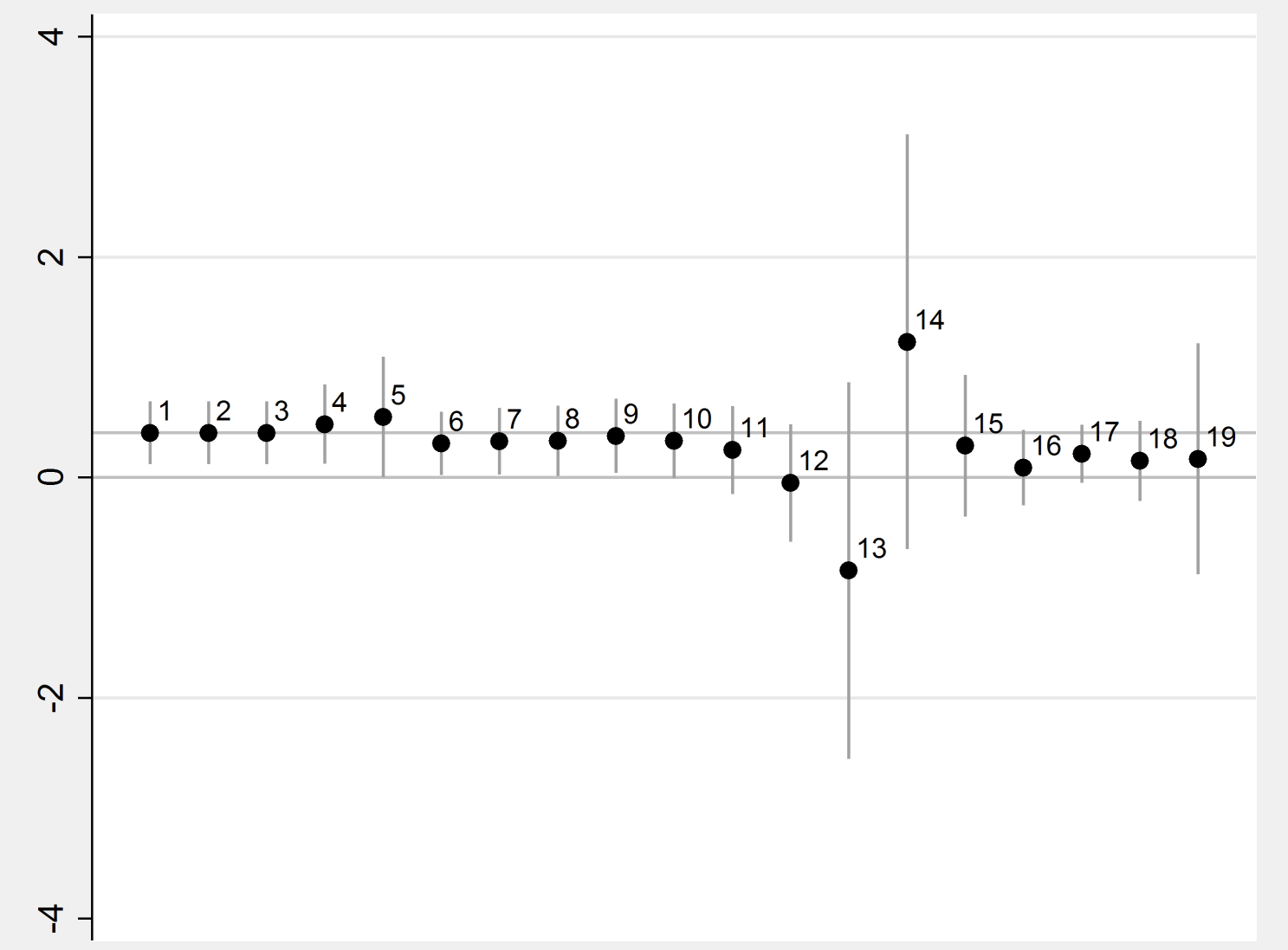

Notes: See notes to Figure A1. 
Figure A3: Robustness Checks: Age at First Birth

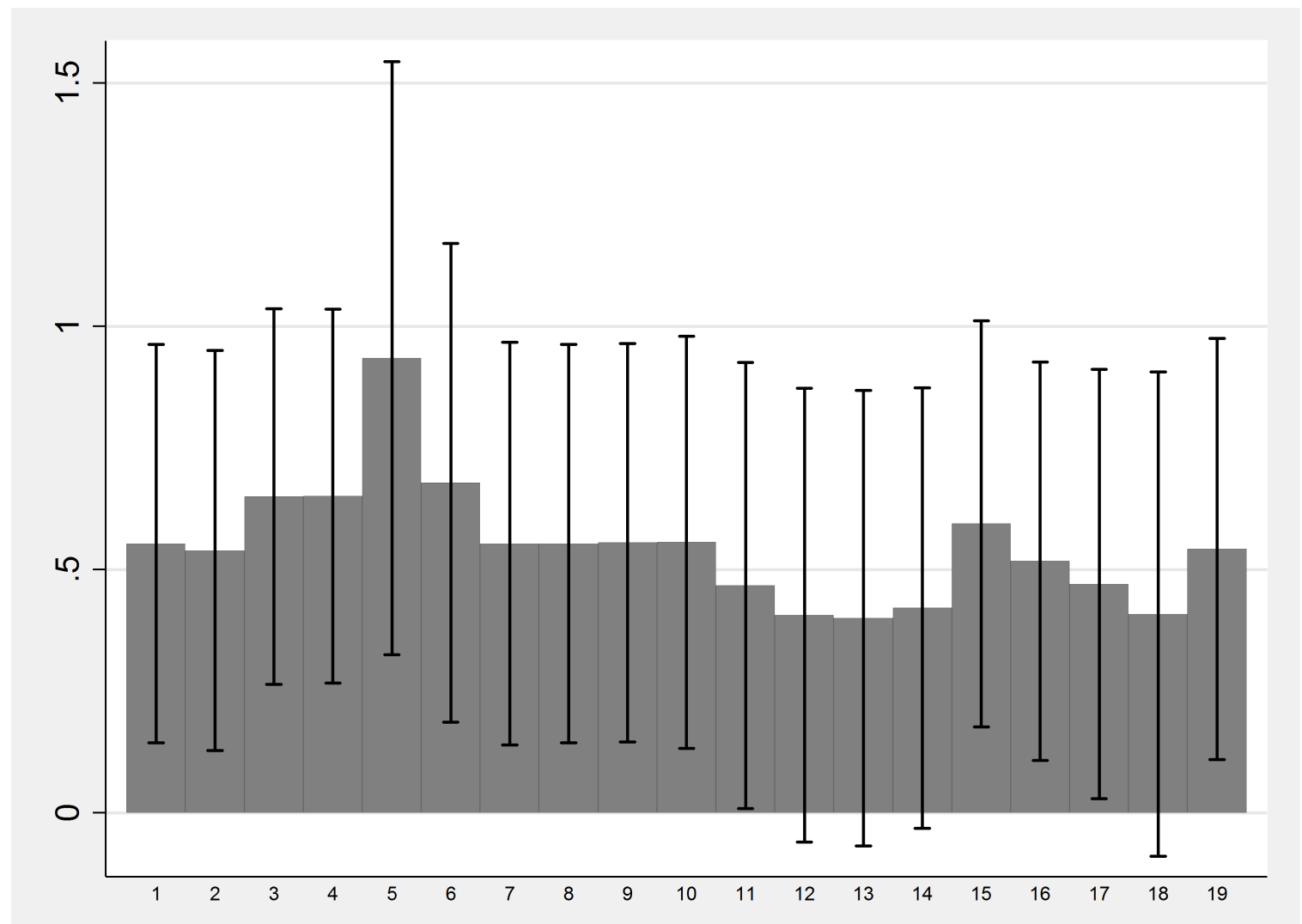

Notes: Each specification corresponds to a 2SLS estimate and the wiskers represent the $95 \%$ confidence interval.

1. Is the 2SLS baseline specification. 2. Excludes post expansion dummy from the instrument set and instead includes it as a control variable. 3. Baseline plus 1970 and 1971 cohort dummies are included in the instrument set. 4. Baseline plus 1971 cohort dummy is included in the instrument set. 5. A single 1972-75 chort dummy plus post-expansion dummy form the instruments set. 6 . We use three instruments, one for cohorts 1972-73, one for cohorts 1974-75, and one for a postexpansion dummy. 7. Age dummies replace age specification in the baseline specification. 8. Age cubic additionally included to the baseline specification. 9. Age quartic additionally included to the baseline specification. 10. Year of birth cubic and age quartic both additionally included. 11. Cohort age interaction included. 12. Cohort age interaction and its square included. 13. Cohort age interaction, its square and cubic included. 14. Cohort age interaction, its square, cubic and quartic included. 15. The sample restricted to those aged 21 to 35. 16. The sample restricted to the cohorts 1965-1979. 17. The sample restricted to the cohorts 1966-1979. 18. The sample restricted to the cohorts 1967-1979. 19. LIML is used instead of 2SLS. 
Figure A4: Robustness Checks: Birth After the Age of 27

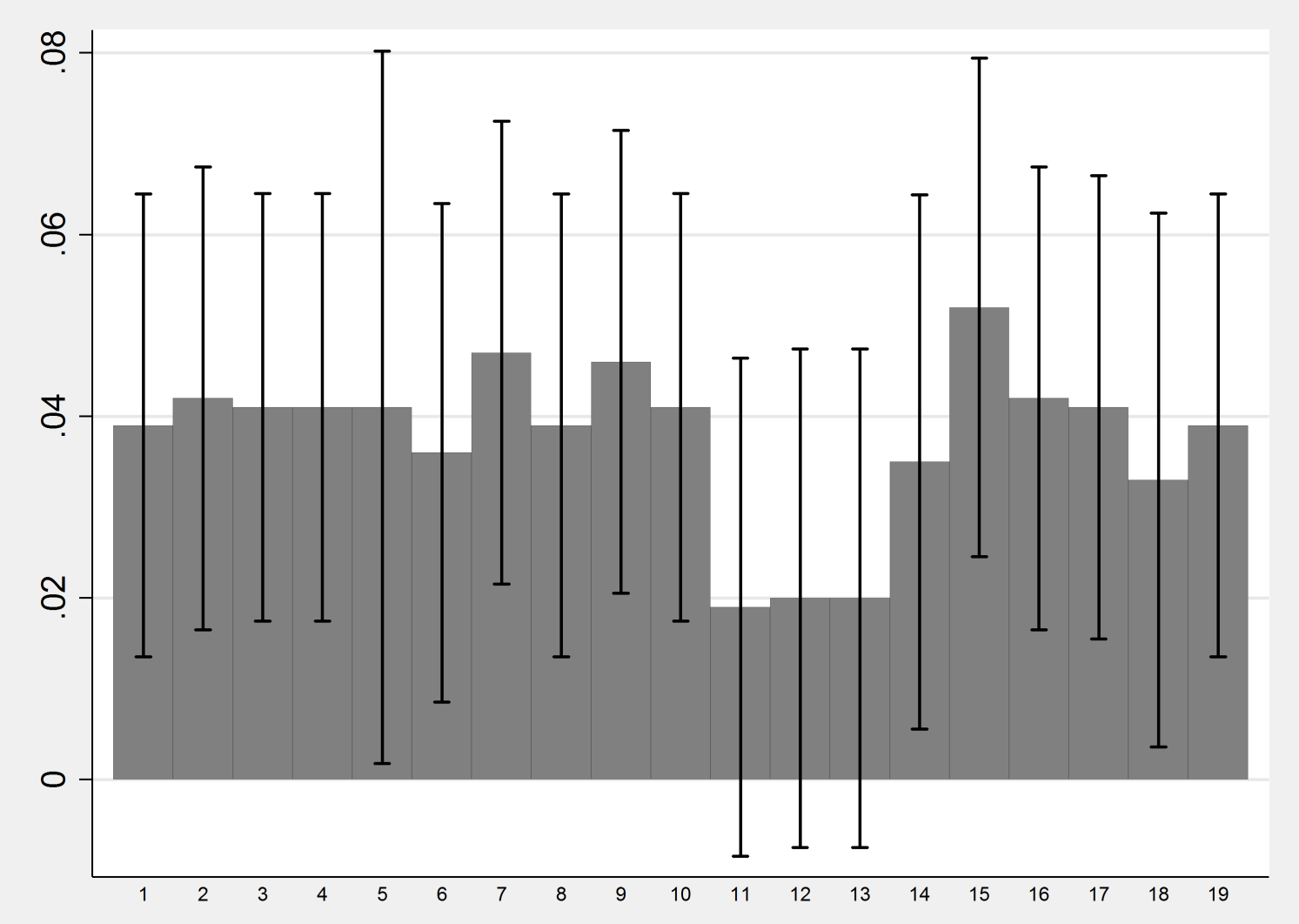

Notes: See notes to Figure A3. 
Figure A5: Robustness Checks: Birth After the Age of 30

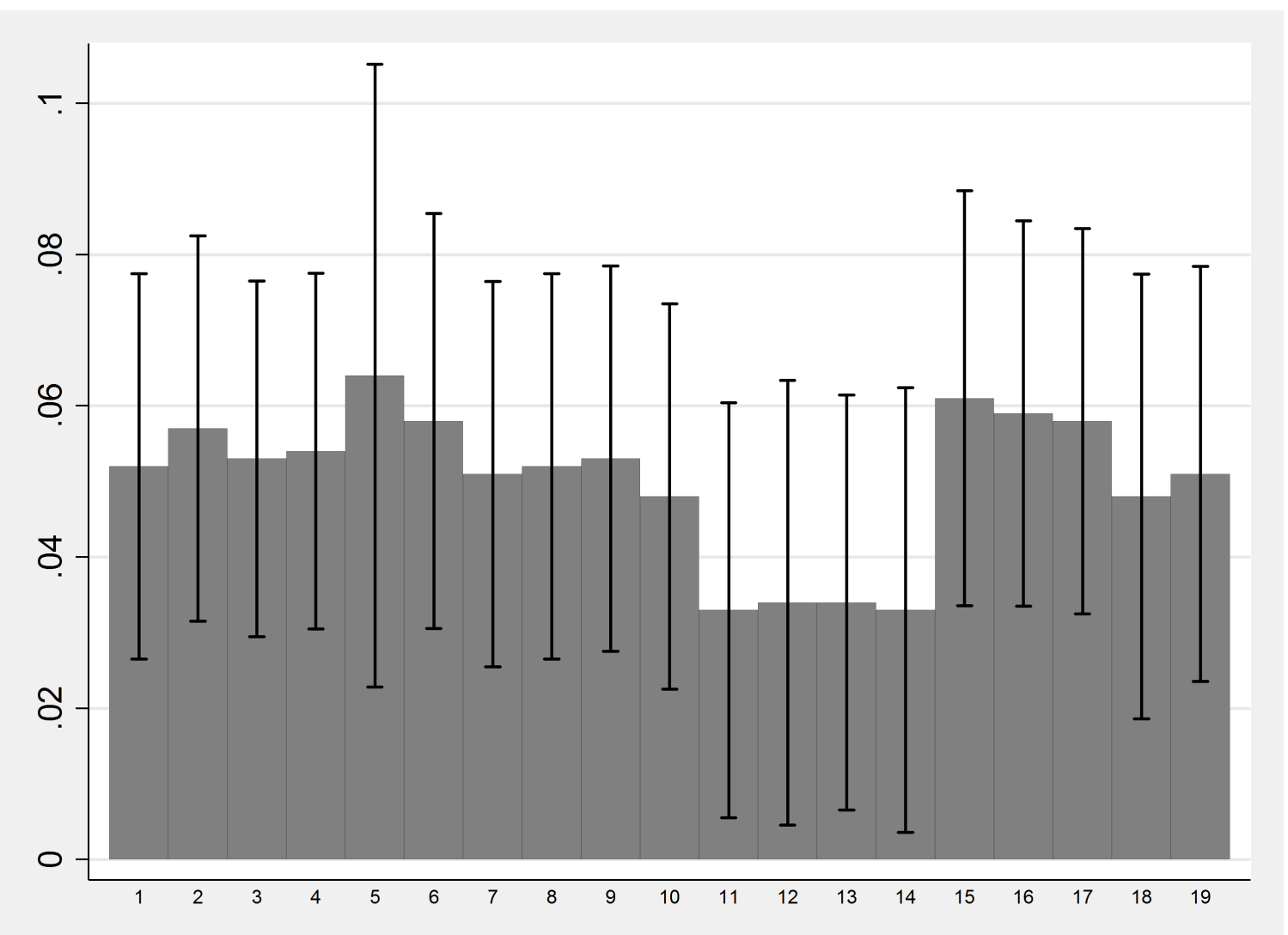

Notes: See notes to Figure A3. 
Table A1: Summary Statistics of Age and Education Variables by Cohort (Education Expansion)

\begin{tabular}{rrrrrrrr}
\hline Cohort & Age & Max Age & Min Age & $\begin{array}{c}\text { Age left } \\
\text { full-time } \\
\text { education }\end{array}$ & Post 16 & Degree & $\begin{array}{c}\text { No } \\
\text { Qualifications }\end{array}$ \\
\hline 62 & 24.9 & 35 & 15 & 16.9 & 0.37 & 0.08 & 0.19 \\
63 & 24.8 & 35 & 15 & 16.9 & 0.38 & 0.08 & 0.18 \\
64 & 24.4 & 35 & 15 & 16.9 & 0.40 & 0.08 & 0.17 \\
65 & 24.1 & 35 & 17 & 17.0 & 0.43 & 0.07 & 0.15 \\
66 & 23.8 & 35 & 16 & 16.9 & 0.42 & 0.07 & 0.16 \\
67 & 24.0 & 35 & 16 & 16.9 & 0.39 & 0.07 & 0.15 \\
68 & 24.1 & 35 & 15 & 16.9 & 0.38 & 0.07 & 0.14 \\
69 & 24.4 & 35 & 16 & 16.9 & 0.38 & 0.08 & 0.14 \\
70 & 24.7 & 35 & 16 & 16.9 & 0.37 & 0.09 & 0.15 \\
71 & 25.2 & 35 & 16 & 17.1 & 0.40 & 0.10 & 0.15 \\
72 & 25.6 & 35 & 16 & 17.3 & 0.43 & 0.13 & 0.13 \\
73 & 25.7 & 35 & 16 & 17.5 & 0.44 & 0.16 & 0.13 \\
74 & 26.3 & 35 & 16 & 17.7 & 0.48 & 0.19 & 0.12 \\
75 & 26.8 & 35 & 16 & 18.0 & 0.57 & 0.22 & 0.10 \\
76 & 26.7 & 35 & 16 & 18.1 & 0.60 & 0.23 & 0.10 \\
77 & 26.7 & 35 & 16 & 18.2 & 0.62 & 0.25 & 0.09 \\
78 & 26.3 & 35 & 16 & 18.1 & 0.61 & 0.25 & 0.09 \\
79 & 25.5 & 34 & 16 & 18.0 & 0.60 & 0.24 & 0.10 \\
& & & & & & & 0.15 \\
\hline Total & 24.9 & 35 & 16 & 17.1 & 0.43 & 0.11 & \\
\hline
\end{tabular}

Notes: Data: LFS 1975-2013. Women aged 35 and younger included in the sample and those born between 1962 and 1979. 
Table A2: Summary Statistics of Age at First Birth and Birth Before a Specific Age (16 to 21) by Cohort (Education Expansion)

\begin{tabular}{rrrrrrrr}
\hline Cohort & Age first birth & \multicolumn{6}{c}{ Age first birth before } \\
& & 16 & 17 & 18 & 19 & 20 & 21 \\
\hline 62 & 22.4 & 0.005 & 0.011 & 0.029 & 0.059 & 0.099 & 0.140 \\
63 & 22.4 & 0.005 & 0.012 & 0.029 & 0.059 & 0.098 & 0.142 \\
64 & 22.4 & 0.004 & 0.010 & 0.027 & 0.057 & 0.095 & 0.129 \\
65 & 22.7 & 0.004 & 0.010 & 0.025 & 0.054 & 0.086 & 0.123 \\
66 & 22.8 & 0.005 & 0.009 & 0.023 & 0.048 & 0.078 & 0.109 \\
67 & 22.9 & 0.004 & 0.009 & 0.023 & 0.048 & 0.081 & 0.113 \\
68 & 23.0 & 0.003 & 0.008 & 0.022 & 0.049 & 0.082 & 0.113 \\
69 & 22.9 & 0.003 & 0.007 & 0.024 & 0.054 & 0.090 & 0.121 \\
70 & 23.0 & 0.003 & 0.009 & 0.025 & 0.058 & 0.088 & 0.123 \\
71 & 23.2 & 0.003 & 0.011 & 0.027 & 0.056 & 0.087 & 0.121 \\
72 & 23.3 & 0.005 & 0.010 & 0.028 & 0.059 & 0.094 & 0.128 \\
73 & 23.5 & 0.004 & 0.010 & 0.027 & 0.054 & 0.088 & 0.123 \\
74 & 23.5 & 0.005 & 0.011 & 0.028 & 0.057 & 0.090 & 0.124 \\
75 & 23.3 & 0.004 & 0.013 & 0.032 & 0.065 & 0.104 & 0.142 \\
76 & 23.3 & 0.002 & 0.010 & 0.028 & 0.064 & 0.105 & 0.144 \\
77 & 23.6 & 0.004 & 0.008 & 0.026 & 0.060 & 0.098 & 0.139 \\
78 & 23.2 & 0.005 & 0.012 & 0.033 & 0.068 & 0.110 & 0.152 \\
79 & 22.6 & 0.003 & 0.012 & 0.041 & 0.074 & 0.111 & 0.153 \\
& & & & & & & \\
Total & 22.9 & 0.004 & 0.010 & 0.027 & 0.056 & 0.091 & 0.127 \\
\hline
\end{tabular}

Notes: Data: LFS 1975-2013. Women aged 35 and younger included in the sample and those born between 1962 and 1979 . 
Table A3: Summary Statistics of Age at First Birth After a Specific Age (21-30) by Cohort (Education Expansion)

\begin{tabular}{rrrrrrrrrrrr}
\hline Cohort & \multicolumn{1}{c}{ Age of birth by or after } \\
& 21 & 22 & 23 & 24 & 25 & 26 & 27 & 28 & 29 & 30 \\
\hline 62 & 0.860 & 0.814 & 0.775 & 0.733 & 0.701 & 0.673 & 0.651 & 0.632 & 0.616 & 0.606 \\
63 & 0.858 & 0.818 & 0.782 & 0.748 & 0.716 & 0.689 & 0.668 & 0.648 & 0.637 & 0.629 \\
64 & 0.871 & 0.833 & 0.797 & 0.765 & 0.736 & 0.713 & 0.693 & 0.678 & 0.668 & 0.660 \\
65 & 0.877 & 0.846 & 0.817 & 0.787 & 0.761 & 0.738 & 0.720 & 0.703 & 0.691 & 0.681 \\
66 & 0.891 & 0.862 & 0.836 & 0.811 & 0.785 & 0.765 & 0.747 & 0.733 & 0.722 & 0.711 \\
67 & 0.887 & 0.856 & 0.827 & 0.803 & 0.781 & 0.760 & 0.740 & 0.725 & 0.712 & 0.700 \\
68 & 0.887 & 0.860 & 0.832 & 0.809 & 0.787 & 0.766 & 0.750 & 0.733 & 0.717 & 0.704 \\
69 & 0.879 & 0.850 & 0.823 & 0.798 & 0.776 & 0.752 & 0.732 & 0.713 & 0.696 & 0.683 \\
70 & 0.877 & 0.850 & 0.823 & 0.798 & 0.776 & 0.756 & 0.736 & 0.716 & 0.698 & 0.684 \\
71 & 0.879 & 0.852 & 0.825 & 0.801 & 0.774 & 0.751 & 0.727 & 0.706 & 0.687 & 0.671 \\
72 & 0.872 & 0.844 & 0.815 & 0.788 & 0.765 & 0.738 & 0.715 & 0.692 & 0.673 & 0.661 \\
73 & 0.877 & 0.847 & 0.819 & 0.797 & 0.771 & 0.746 & 0.728 & 0.706 & 0.687 & 0.672 \\
74 & 0.876 & 0.843 & 0.812 & 0.782 & 0.755 & 0.731 & 0.710 & 0.691 & 0.676 & 0.659 \\
75 & 0.858 & 0.823 & 0.795 & 0.765 & 0.742 & 0.718 & 0.698 & 0.678 & 0.652 & 0.635 \\
76 & 0.856 & 0.815 & 0.783 & 0.754 & 0.728 & 0.707 & 0.685 & 0.662 & 0.640 & 0.622 \\
77 & 0.861 & 0.826 & 0.792 & 0.764 & 0.740 & 0.718 & 0.696 & 0.676 & 0.656 & 0.633 \\
78 & 0.848 & 0.809 & 0.776 & 0.753 & 0.734 & 0.712 & 0.695 & 0.671 & 0.650 & 0.629 \\
79 & 0.847 & 0.815 & 0.784 & 0.762 & 0.738 & 0.719 & 0.698 & 0.676 & 0.660 & 0.644 \\
& & & & & & & & & & \\
Total & 0.873 & 0.839 & 0.809 & 0.780 & 0.754 & 0.731 & 0.711 & 0.693 & 0.677 & 0.665 \\
\hline
\end{tabular}

Notes: Data: LFS 1975-2013. Women aged 35 and younger included in the sample and those born between 1962 and 1979. 
Table A4: Family Background Characteristics (Easter Leaving Rule)

\begin{tabular}{|c|c|c|c|c|c|c|c|c|}
\hline & $(1)$ & $(2)$ & $(3)$ & $(4)$ & $(5)$ & (6) & $(7)$ & (8) \\
\hline & \multicolumn{2}{|c|}{ Degree } & \multicolumn{2}{|c|}{ Post School Quals } & \multicolumn{2}{|c|}{ Some Quals } & \multicolumn{2}{|c|}{ No quals or schooling } \\
\hline & Father & Mother & Father & Mother & Father & Mother & Father & Mother \\
\hline $\mathrm{RD}$ & $\begin{array}{r}-0.00927 \\
(0.0432)\end{array}$ & $\begin{array}{l}-0.0316 \\
(0.0338)\end{array}$ & $\begin{array}{c}0.0122 \\
(0.0705)\end{array}$ & $\begin{array}{l}-0.0123 \\
(0.0600)\end{array}$ & $\begin{array}{c}0.00480 \\
(0.0766)\end{array}$ & $\begin{array}{c}0.0192 \\
(0.0766)\end{array}$ & $\begin{array}{c}0.00660 \\
(0.0739)\end{array}$ & $\begin{array}{l}-0.0247 \\
(0.0755)\end{array}$ \\
\hline Observations & 2,339 & 2,340 & 2,339 & 2,340 & 2,339 & 2,340 & 2,339 & 2,340 \\
\hline R-squared & 0.021 & 0.008 & 0.004 & 0.005 & 0.020 & 0.021 & 0.015 & 0.019 \\
\hline RD-DD & $\begin{array}{l}-0.0116 \\
(0.0142)\end{array}$ & $\begin{array}{r}-0.00387 \\
(0.0105)\end{array}$ & $\begin{array}{l}-0.0139 \\
(0.0253)\end{array}$ & $\begin{array}{c}0.00744 \\
(0.0197)\end{array}$ & $\begin{array}{c}-0.0256 \\
(0.0280)\end{array}$ & $\begin{array}{r}-0.00113 \\
(0.0266)\end{array}$ & $\begin{array}{c}-0.0175 \\
(0.0284)\end{array}$ & $\begin{array}{l}-0.0225 \\
(0.0279)\end{array}$ \\
\hline Observations & 4,852 & 4,860 & 4,852 & 4,860 & 4,852 & 4,860 & 4,852 & 4,860 \\
\hline$R^{2}$ & 0.023 & 0.012 & 0.014 & 0.026 & 0.043 & 0.078 & 0.036 & 0.074 \\
\hline
\end{tabular}

Notes: Data: 1st Wave Understanding Society. In the RD specifications the sample includes women born between September 1957 and 1969, the RD-DD sample includes women born between 1940 and 1969. In both samples the month of births are restricted to between September and June. Degree $(=1)$ if the parent had a degree, 0 otherwise. Post School Quals $(=1)$ if the parent had some post school qualifications or above (i.e. including degree), 0 otherwise. Some Quals (=1) if the individual indicates that the parent had some qualifications or above, 0 otherwise. No quals or schooling $(=1)$ if the parent left school with no qualifications or did not go to school at all, 0 otherwise. All specifications include a indicator for being non-white, a cubic polynomial in age and quadratic in year of birth, centered month of birth quadratic and a quadratic spline. 
Table A5: Family Background Characteristics (Education Expansion)

\begin{tabular}{|c|c|c|c|c|c|c|c|c|}
\hline & (1) & $(2)$ & $(3)$ & (4) & $(5)$ & (6) & $(7)$ & (8) \\
\hline & \multicolumn{2}{|c|}{ Degree } & \multicolumn{2}{|c|}{ Post School Quals } & \multicolumn{2}{|c|}{ Some Quals } & \multicolumn{2}{|c|}{ No quals or schooling } \\
\hline & Father & Mother & Father & Mother & Father & Mother & Father & Mother \\
\hline \multirow[t]{2}{*}{ Cohort 1972} & 0.018 & 0.010 & -0.018 & 0.005 & 0.004 & 0.022 & 0.017 & 0.008 \\
\hline & $(0.024)$ & $(0.020)$ & $(0.035)$ & $(0.031)$ & $(0.037)$ & $(0.037)$ & $(0.035)$ & $(0.035)$ \\
\hline \multirow{2}{*}{ Cohort 1973} & 0.033 & -0.013 & 0.049 & 0.014 & -0.030 & -0.049 & 0.023 & 0.043 \\
\hline & $(0.025)$ & $(0.018)$ & $(0.036)$ & $(0.032)$ & $(0.037)$ & $(0.037)$ & $(0.035)$ & $(0.036)$ \\
\hline \multirow[t]{2}{*}{ Cohort 1974} & -0.012 & -0.000 & -0.045 & -0.008 & -0.047 & -0.040 & 0.023 & 0.032 \\
\hline & $(0.025)$ & $(0.022)$ & $(0.037)$ & $(0.034)$ & $(0.040)$ & $(0.040)$ & $(0.038)$ & $(0.038)$ \\
\hline \multirow[t]{2}{*}{ Cohort 1975} & -0.015 & -0.019 & 0.037 & -0.015 & $0.070^{*}$ & 0.006 & $-0.063^{*}$ & -0.003 \\
\hline & $(0.027)$ & $(0.022)$ & $(0.041)$ & $(0.036)$ & $(0.041)$ & $(0.041)$ & $(0.037)$ & $(0.039)$ \\
\hline \multirow{2}{*}{ Post EE } & 0.019 & 0.006 & 0.013 & -0.020 & -0.006 & -0.037 & -0.049 & 0.004 \\
\hline & $(0.037)$ & $(0.032)$ & $(0.051)$ & $(0.046)$ & $(0.052)$ & $(0.051)$ & $(0.047)$ & $(0.048)$ \\
\hline \multirow[t]{2}{*}{ Constant } & $5.049^{*}$ & $4.512^{*}$ & $8.179^{*}$ & $9.480 * *$ & $11.236^{* *}$ & $12.061^{* * *}$ & -4.410 & -7.067 \\
\hline & $(3.016)$ & $(2.477)$ & $(4.254)$ & $(3.967)$ & $(4.412)$ & $(4.461)$ & $(4.704)$ & $(4.440)$ \\
\hline Observations & 4,135 & 4,134 & 4,135 & 4,134 & 4,135 & 4,134 & 4,135 & 4,134 \\
\hline$R^{2}$ & 0.024 & 0.016 & 0.004 & 0.009 & 0.010 & 0.019 & 0.009 & 0.026 \\
\hline$F$-test & 0.84 & 0.47 & 1.22 & 0.13 & 1.56 & 0.80 & 1.21 & 0.43 \\
\hline p-value & 0.52 & 0.80 & 0.30 & 0.98 & 0.17 & 0.55 & 0.30 & 0.83 \\
\hline
\end{tabular}

$(=1)$ if the parent had a degree, 0 otherwise. Post School Quals $(=1)$ if the parent had some post school qualifications or above (i.e. including degree), 0 otherwise. Some Quals $(=1)$ if the individual indicates that the parent had some qualifications or above, 0 otherwise. No quals or schooling $(=1)$ if the parent left school with no qualifications or did not go to school at all, 0 otherwise. All specifications include a indicator for being non-white, a cubic polynomial in age and quadratic in year of birth. 